\title{
Two types of deverbal nominalization in Northern Paiute*
}

\author{
Maziar Toosarvandani \\ Massachusetts Institute of Technology
}

March 4, 2013

\begin{abstract}
Why do nominalizations mean what they do? I investigate two deverbal nominalizers in Northern Paiute (Uto-Aztecan, Numic: Western United States), $-n a$ and $-d \dot{t}$, both of which can create nominalizations that describe either an event (like the POSS-ing gerund in English) or an individual (like agent nominalizations with -er). I propose a syntax and semantics for these deverbal nominalizations that accounts for their interpretive variability. On the syntax side, I argue that $-n a$ and $-d \dot{t}$ overtly realize the nominal functional head that canonically assigns case to possessors, when this head takes a vP complement. On the semantics side, I propose that Northern Paiute has operators that abstract over a variable inside the nominalization. This accounts for the meanings that nominalizations in Northern Paiute have, and it highlights their relationship to nominalization patterns in other languages.
\end{abstract}

\section{Introduction}

Northern Paiute - a Uto-Aztecan language of the Numic branch spoken across the western United States - has two types of deverbal nominalization that describe either events or individuals. ${ }^{1}$ When the nominalizer suffixes $-n a$ or $-d \dot{t}$ attach to a verb, they create a nominalization that can

${ }^{*}$ I thank Grace Dick, Leona Dick, Morris Jack, Elaine Lundy, Edith McCann, Meg McDonald, and Madeline Stevens for teaching me about their language. I am also grateful to Rebecca Cover for our early discussions of the Northern Paiute data, as well as to Rajesh Bhatt, Annahita Farudi, Andrew Garrett, Michael Houser, Kyle Johnson, Line Mikkelsen, Tom Roeper, Andrés Salanova, Tim Thornes, and audiences at Cornell University, McGill University, the Massachusetts Institute of Technology, Stanford University, the University of California (Berkeley, Los Angeles, and Santa Cruz), the University of Massachusetts, Amherst, and the University of Ottawa for their very helpful suggestions and questions. This research was generously funded by a Jacobs Research Fund Grant (Whatcom Museum Foundation, Bellingham, Washington), Phillips Fund Grant (American Philosophical Society, Philadelphia), a Grant in Great Basin Studies from the Sven and Astrid Liljeblad Endowment Fund (University of Nevada, Reno), and a grant from the Survey of California and Other Indian Languages (University of California, Berkeley).

${ }^{1}$ Northern Paiute is comprised of several closely related dialects that are spoken across and immediately adjacent to the Great Basin (Babel et al., to appear). Most of the data presented here come from my own fieldwork on the Mono Lake variety, spoken at Mono Lake in eastern California and immediately to the north in Bridgeport and Coleville, California and Sweetwater, Nevada. Additional data comes from the Burns, Oregon variety (Thornes 2003), and to a lesser extent the McDermitt, Nevada variety (Snapp et al. 1982) and the Bannock variety spoken at Fort Hall, Idaho (Liljeblad 1966). For all dialects of Northern Paiute, there are probably no more than 300 fluent speakers today (Golla 2011:174), and for the Mono Lake dialect, there are around five speakers. 
refer to the event described by the verb, as in (1a) and (2a). Or, when one of the verb's arguments is gapped, they create a nominalization that describes that individual, as in (1b) and (2b). ${ }^{2}$
a. $\mathrm{Niq}$ a=bbauma-winni-na naka.
1SG.NOM 4.GEN=rain-STAT-NMLZ hear
'I hear it raining.' (elicitation, MS, BP37-1-s, 6)
$\begin{array}{ll}\text { b. I=saa-na } & \text { ne-hu. } \\ \text { 1SG.GEN=cook-NMLZ burn-PUNC }\end{array}$
'What I was cooking burned.' (elicitation, EM, BP32-9-s, 15)
(2) $\quad$ a. Nii pauma-winni-di naka.
1SG.NOM rain-STAT-NMLZ hear
'I hear it raining.' (elicitation, MS, BP37-1-s, 5)
$\begin{array}{llll}\text { b. } & \text { Su=kutsu } \quad \text { patsa-di } & \text { mia-hu. } \\ \text { DEF.NOM=cow kill.SG-NMLZ go-PUNC }\end{array}$
'The cow killer left.' (elicitation, EM, BP37-1-s, 16)

In (1b), the patient of the verb saa 'cook' is gapped, so the nominalization describes the individual that the speaker cooks; in (2b), the agent of the verb patsa 'kill (sg.)' is gapped, so the nominalization describes the individual that kills the cow.

This semantic variability is surprising when we compare the nominalization patterns in (1a-b) and (2a-b) to structurally similar ones in English. The POSS-ing gerund, in Abney's (1987) terms, describes an event (3a), but it is not able to refer to an individual, such as the agent (3b) or patient (3c) of the burning.
a. I witnessed Caesar's burning the city.
b. * Burning the city was arrested.
Intended: 'The one who burnt the city was arrested.'
c. * Caesar's burning was rebuilt within the year.
Intended: 'What Caesar burnt was rebuilt within the year.'

Instead, English uses a different series of nominalizers to describe individuals. For instance, the -er suffix creates nominalizations that pick out the external argument of the verb, as in (4a) (Rappaport Hovav and Levin 1992). It is not able to create event-denoting nominalizations (4b). ${ }^{3}$

\footnotetext{
${ }^{2}$ Each example from my own fieldwork is annotated with its type (dialogue, elicitation, narrative, or prompted narrative), the speaker's initials, the identification number for its source (starting with BP), and its location in the source (either a line number or timestamp). Examples from other sources receive the usual parenthetical citation.

I use the following abbreviations in this paper: $\mathrm{ACC}=$ accusative, $\mathrm{APPL}=$ applicative, $\mathrm{DEF}=$ definite, $\mathrm{DEM}=$ demonstrative, $\mathrm{DIM}=$ diminutive, $\mathrm{DUR}=$ durative, $\mathrm{EMPH}=$ emphatic particle, $\mathrm{EXCL}=$ exclusive, $\mathrm{FOC}=$ focus prefix, GEN = genitive, $\mathrm{INCH}=$ inchoative, $\mathrm{INCL}=$ inclusive, $\mathrm{IND}=$ indicative, $\mathrm{IP}=$ instrumental prefix, $\mathrm{IRR}=$ irrealis, $\mathrm{LOC}$ $=$ locatival postposition, $\mathrm{MOD}=$ modal particle, $\mathrm{MOT}=$ motion suffix, $\mathrm{NEG}=$ negation, $\mathrm{NMLZ}=$ nominalizer, $\mathrm{NOM}$ $=$ nominative, $\mathrm{NSP}=$ nonspecific patient, $\mathrm{PASS}=$ passive, $\mathrm{PL}=$ plural, $\mathrm{PLUR}=$ pluractional, $\mathrm{PRF}=$ perfect, $\mathrm{PRO}=$ resumptive pronoun, $\mathrm{PROSP}=$ prospective aspect, $\mathrm{PTC}=$ discourse particle, $\mathrm{REFL}=$ genitive reflexive anaphor, $\mathrm{SBJ}=$ subject, SBJV $=$ subjunctive, $\mathrm{SEQ}=$ sequential marker, $\mathrm{SG}=$ singular, $\mathrm{STAT}=$ stative aspect, $\mathrm{TNS}=$ 'general' tense (Thornes 2003:398).

${ }^{3}$ The exception is derived nominals that exhibit the process-result ambiguity (Grimshaw 1990:46-63). A derived nominal like destruction can describe an event of destruction, or it can describe the result of that event. Observe,
} 
a. The seller of counterfeit stock was jailed.

b. * I witnessed the seller of counterfeit stock.

Intended: 'I witnessed the selling of counterfeit stock.'

Why do nominalizations in Northern Paiute permit both event and individual interpretations, while their correlates in English do not? In this paper, I give a syntax and semantics for deverbal nominalization in Northern Paiute that accounts for its interpretive variability.

I start by exploring the syntax of deverbal nominalizations in Northern Paiute. Assuming that they contain a verbal projection embedded inside a nominal one (Bresnan 1997, Borsley and Kornfilt 2000), I propose in $\$ 2$ that the nominalizers - na and - $d \dot{t}$ realize the nominal functional category that canonically assigns case to possessors, when it embeds a vP:

(5)

a.

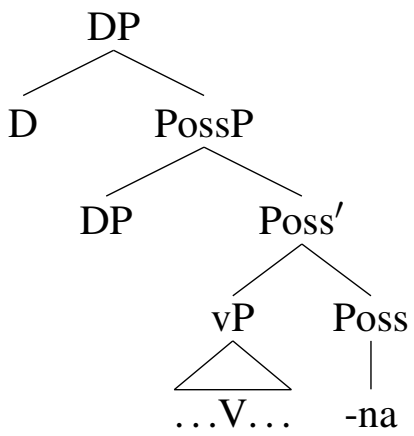

b.

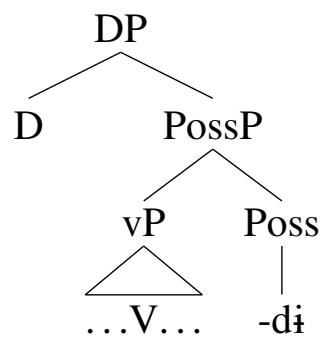

This nominal head, which I call Poss, is the analogue of T(ense) in the verbal domain (Szabolcsi 1983, 1987, 1994, Cardinaletti 1998, Alexiadou et al. 2007:556-575). Since these nominalizations do not contain $\mathrm{T}$, nominative case is not available inside them. The -na nominalizer does make an additional genitive case available to the DP in the specifier position it projects. The $-d \dot{t}$ nominalizer, however, is defective and does not project a specifier position or assign genitive case, leaving one case too few in the nominalizations it creates.

With these structures in hand, I then turn to the semantics of deverbal nominalization in Northern Paiute. In $\S 3$, I show that the event interpretation of nominalizations with -na comes for free, in a way. Since the nominalizer makes available a genitive case to the highest argument of the verb, all its individual-type arguments can be saturated. Assuming that the verb also takes an event argument (Davidson 1967), only the event argument will then be left unsaturated, so that the nominalization describes an event. On the other hand, the individual interpretation arises because Northern Paiute has operators inside the DP that can abstract over the variable contributed by a (sometimes null) resumptive pronoun. These resumptive pronouns are projected syntactically, creating a gap in direct object position, as in (2a), or in the argument position of a postposition, as in (6).

however, that the result is not itself an argument of the verb destroy - it describes not the thing destroyed but the effects of the destruction. In addition, as Borer (2003) observes, the so-called result interpretation is not always so easily characterized as the result of an event. For instance, under their 'result' meanings, obstruction describes something like the causer of an event, administration the agent, and entrance a location. The precise nature of the result interpretation depends on a variety of factors, including the Aktionsart of the nominalized verb and whether it is a verb of creation (Asher 1993:150-159, Pustejovsky 1995:170f.).

This is very different from the semantic variability exhibited by the two types of deverbal nominalization I describe in Northern Paiute, which as I will shortly show always describe an argument of the embedded verb under their individual interpretations. 


$$
\begin{aligned}
& \text { Ka=i=naa'a pi-kuba kati-na niti timi-dua. } \\
& \text { DEF.ACC=1SG.GEN=father PRO-LOC sit-NMLz 1SG.NOM buy-IRR } \\
& \text { 'I will buy the one my father is sitting on.' (elicitation, MS, BP34-5-s, 6) }
\end{aligned}
$$

Because of the antilocality property of resumptive pronouns (Borer 1984, McCloskey 1990), nominalizations with -na can describe any individual that is not the highest argument of the embedded verb (the surface subject, in other words).

In contrast, when nominalizations created by $-d \dot{t}$ describe an individual, they invariably describe the highest argument of the verb. This might be the agent, as in (2b) above, though it can also be the patient of a passive or unaccusative verb, as in $(7 a-b)$, or the sole argument of a stative predicate, as in $(7 \mathrm{c})$.
a. Su=na-gwitama-di
wadzi-mia-hu.
DEF.NOM=PASS-lock.up-NMLZ hide-go-PUNC
'The one who should be locked up ran away.' (elicitation, MS, BP34-4-s, 24)
b. Ka=idziggwi ka=kwopika-winni-di nił
DEF.ACC=blanket DEF.ACC=shiver-STAT-NMLZ 1 SG.NOM give.DUR
'I gave the blanket to the one who is shivering.' (elicitation, MS, BP34-3-s, 28)
$\begin{array}{lll}\text { c. } & \text { Su=nana } & \text { ka=patsiponoa-di-ma } \\ \text { DEF.NOM=man } & \text { DEF.ACC=be.round-NMLZ-LOC sit-PUNC }\end{array}$
'The man sat on the round thing.' (elicitation, EM, BP34-3-s, 34)

In $\S 4$, I propose that because these nominalizations do not contain nominative case - and because genitive case is also not available - the highest argument of the verb must be realized as a phonologically null argument (PRO) that is abstracted over by an operator to derive the individual interpretation. As an additional consequence, the only time nominalizations with $-d \dot{t}$ can describe an event is when the verb does not take any individual arguments at all.

In §5, I explore why the English nominalizations in (3-4) do not exhibit the same semantic variability that nominalizations with $-n a$ and $-d i$ in Northern Paiute do. The POSS-ing gerund in fact has much the same structure as a nominalization with - na. Yet, it only has an event interpretation, I argue, because English lacks the system of operators and resumptive pronouns found in Northern Paiute. As for the other nominalization pattern, the -er suffix in English might at first glance resemble $-d \dot{t}$, but its syntax and semantics are actually quite different. The nominalizer itself closes off the verb's event argument, so the nominalizations it creates never have an event interpretation.

\section{Two deverbal nominalizers in Northern Paiute}

Deverbal nominalizations share properties of both nouns and verbs. On the one hand, they have the external distribution of a nominal category. The nominalizations created by $-n a$ and $-d \dot{t}$ in Northern Paiute can, for instance, serve as the argument of a verb, as in (8a-b), or as the argument of a postposition, as in (9a-b).

$$
\begin{aligned}
& \text { a. Su=nana } \quad \text { patsa-na } \quad \text { oo hapi. } \\
& \text { DEF.NOM=man kill.SG-NMLZ there lie.DUR }
\end{aligned}
$$

'The thing the man killed is lying over there.' (elicitation, EM, BP37-1-s, 18) 


\section{b. Su=kutsu patsa-di mia-hu.}

DEF.NOM=cow kill.SG-NMLZ go-PUNC

'The cow killer left.' (elicitation, EM, BP37-1-s, 16)
a. $\quad \mathrm{Su}=$ pa'mogo $\mathbf{k a}=$ nana $\quad$ ti-batsa-na-gguba kati.
DEF.NOM=frog DEF.ACC=man NSP-kill-NMLZ-LOC sit.DUR
'The frog is sitting on the man's kill.' (elicitation, EM, BP32-7-s, 14)
b. O-no'ona-ggwe nimmi ka=kutsu patsa-di-ggwe
3SG-LOC-LOC 1PL.EXCL.NOM DEF.ACC=cow kill.SG-NMLZ-LOC
mo'o.
walk.DUR.PL

'We walked around the cow killer.' (elicitation, MS, BP34-3-s, 38)

At the same time, deverbal nominalizations have the internal structure of a verbal category. At the very least, looking just at the nominalizations in $(8 a-b)$ and $(9 a-b)$, we can say that they must contain a verb, patsa 'kill (sg.)'.

Within a phrase-structural theory of syntax, the mixed nature of nominalizations can be represented with structures that are, as Bresnan (1997:4) puts it, 'partitioned into two categorially uniform subtrees such that one is embedded as a constituent of the other.' The verb-like properties of a nominalization come from the verbal projection embedded inside the nominal projection (Kornfilt 1984, Borsley and Kornfilt 2000, Kornfilt and Whitman 2011). For Northern Paiute, I propose that $-n a$ and $-d i$ are both realizations of a nominal functional head, which I will call Poss, when it takes a vP complement:

(10)

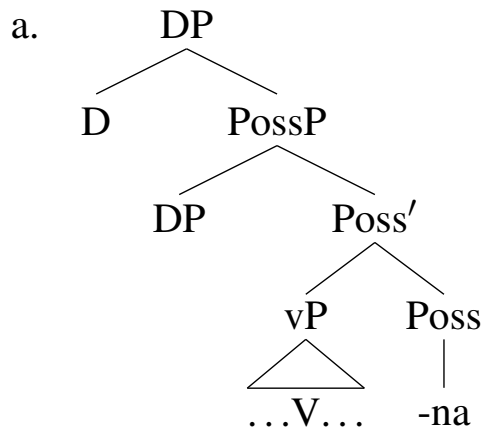

b.

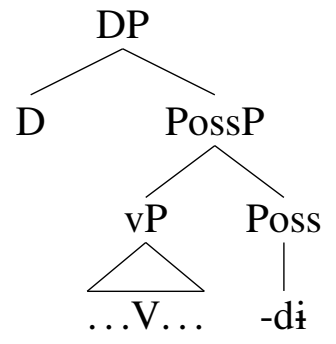

The Poss head canonically assigns case to possessors (Szabolcsi 1983, 1987, 1994, Cardinaletti 1998, Alexiadou et al. 2007:556-575), and in possessive descriptions it would, of course, take a nominal complement. ${ }^{5} \mathrm{I}$ am supposing, however, that Poss can also take a vP complement in

\footnotetext{
${ }^{4}$ Northern Paiute, like other Numic languages, has a robust system of consonant mutation. The first consonant of any morpheme can take up to three different forms - lenis, fortis, or voiced fortis — depending on what the preceding morpheme is. For instance, the initial consonant in patsa 'kill (sg.)' is realized as a lenis stop (b) when it is preceded by the nonspecific patient prefix $t \dot{t}$ - in $(9 \mathrm{c})$, but as voiced fortis stop $(b b)$ when it is preceded by the accusative secondperson singular proclitic pronoun: i.e. $\dot{i}=$ bbatsa 'kill you (sg.)'. See Babel et al. 2012 for details.

${ }^{5}$ The Poss head is sometimes realized overtly in possessive descriptions. In Hungarian, for instance, the possessed noun in a possessive description bears an agreement suffix:

(i) a Péter kalap-ja the Peter hat-3SG
} 
deverbal nominalizations in Northern Paiute. The Poss head that projects a specifier to which it assigns genitive case is realized overtly as the nominalizer - $n a$ when its complement is a vP. I assume that, if Poss is obligatorily present in the extended nominal projection, there must also be a defective version of the head, which does not project a specifier or assign case. This defective Poss would show up in DPs that are not possessive descriptions, and it is realized overtly as - $d \dot{t}$ in deverbal nominalizations.

In the early literature on nominalization, nominalizers were taken to be members of a lexical category, not a functional category as I am proposing. The -ing suffix in POSS-ing gerunds, for instance, was analyzed as an $\mathrm{N}$ that takes a verb phrase complement (Horn 1975, Jackendoff 1977:222f.). This is problematic, though, for a couple of reasons. First, if nominalizers were themselves Ns, they would not have the same type of meaning as other members of this category. We are used to thinking of common nouns as describing a set of entities, but it is clear that the nominalizers do not have this kind of meaning. More importantly, we would expect to be able to substitute a regular noun in the same phrase-structural position as a nominalizer. But Ns do not take verb phrase complements.

Below, I provide support for three important components of my proposal. First, $-n a$ and $-d \dot{t}$ embed a verbal constituent that is the size of a vP, and not one that is larger or smaller. I show in $\$ 2.1$ that the nominalizations they create must contain at least a vP because: i) the direct object receives accusative case, ii) they can contain negation, and iii) they can contain left-edge adverbs. They do not, however, contain a larger constituent because they cannot contain elements that are associated with higher verbal projections like TP and CP.

Second, the two nominalizers in Northern Paiute realize the Poss head. This predicts that nominalizations with - na and - $d \boldsymbol{t}$ should be able to contain any of the categories located above Poss in the extended nominal projection. In $\S 2.2$, I show that this is indeed the case. Both types of nominalizations can occur under a determiner (D) and markers of number.

Third, -na projects a specifier to which it assigns genitive case-like the possessor in a possessive description - while - $d \dot{t}$ does not. In $§ 2.3$, I show that nominalizations with -na do, in fact, always contain a possessor, and in $\S 2.4$, I show that nominalizations with - $d \dot{t}$ never do.

Before moving on, I should point out that if the $-n a$ and $-d \dot{t}$ nominalizers are terminal nodes in the syntax, they must somehow appear as suffixes on the verb. I remain agnostic about how precisely this happens. In a strongly lexicalist framework, such as Lexical Functional Grammar (LFG) or Head-Driven Phrase Structure Grammar (HPSG), there are technically distinct ways of treating nominalization, which conceptually end up being quite similar (see, for instance, Bresnan 1997 and Malouf 2000a,b). It should be possible to translate the insights of the current proposal into a lexicalist framework.

\subsection{The verbal structure of deverbal nominalizations}

Since at least Chomsky 1970, it has been known that deverbal nominalizations form a heterogenous class whose members can be more or less verb-like (a fact also recognized in the typological literature - see Comrie 1976, Koptjevskaja-Tamm 1993:6f., Comrie and Thompson 2007:343-376).

'Peter's hat' (Szabolcsi 1987:171)

Szabolcsi (1987) argues that this agreement suffix is the overt realization of Poss, which agrees in person and number with the possessor in its specifier. (See Abney 1987:37-53 for discussion of similar languages.) 
Some nominalizations, such as the POSs-ing gerund in (3a), resemble a clause to a much greater degree than others, such as the agent nominalization in (4a). If deverbal nominalizations contain a verbal projection embedded inside a nominal one, how verb-like a nominalization is will depend on how large the verbal projection is (Kornfilt 1984, Borsley and Kornfilt 2000, Panagiotidis and Grohmann 2009, Kornfilt and Whitman 2011).

The two types of deverbal nominalization in Northern Paiute exhibit some properties of a clause, but not others. I will argue they embed only a vP, since they are able to contain elements associated just with this verbal projection, and not larger projections such as TP or CP.

\subsubsection{The two nominalizers embed a vP}

There are three pieces of evidence that nominalizations with - na and - $d \dot{t}$ embed a verbal constituent that is at least as big as a vP.

First, direct objects of the verb are realized exactly as they would be in a clause, since $\mathrm{v}$ is present to assign them accusative case (Chomsky 2000:123f.). This means that $k a=o p o$ 'the basket' in (11a) and ka=toogga 'the dog' in (11b) can appear as direct arguments of the verb without the mediation of an adposition.

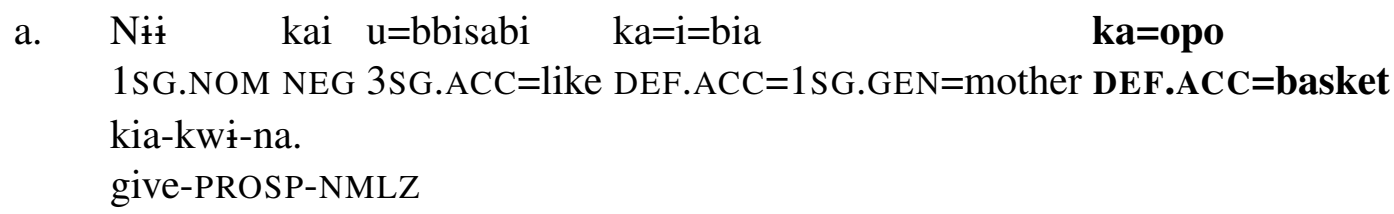

'I don't like the one that my mother is going to give the basket to.' (elicitation, EM, BP35-3-s, 9)

b. $\mathrm{Su}=\mathbf{k a}=$ toogga patsa-di wadzi-mia-hu.

DEF.NOM=DEF.ACC $=$ dog kill.SG-NMLZ hide-go-PUNC

'The one who shot the dog ran away.' (elicitation, MS, BP34-3-s, 45)

Moreover, the definite determiners of the direct objects in (11a-b) bear accusative case and are realized as $k a=$, rather than the nominative $s u=$. Accusative case in Northern Paiute is also manifested morphologically on pronouns. The direct objects of both nominalizations in $(12 \mathrm{a}-\mathrm{b})$ are the first-person singular accusative proclitic pronoun $i=$.
a. Nì siddobbu'i ka=naatsi'i i=diłkwi-na.
1SG.NOM know.DUR DEF.ACC=boy 1SG.ACC=tell-NMLZ
'I believe what the boy told me.' (elicitation, EM, BP35-4-s, 15)
$\begin{array}{ll}\text { b. } & \mathrm{Su}=\mathbf{i}=\text { gwoti-hu-d } \mathbf{i} \\ \text { DEF.3SG=1SG.ACC=shoot-PUNC-NMLZ go-PUNC }\end{array}$
'The one who shot me left.' (elicitation, MS, BP35-4-s, 21)

Second, negation can occur inside both type of nominalization. In Northern Paiute, negation appears either in sentence-initial position, as in (13a), or following the subject at the left edge of the verb phrase, as in (13b) (Thornes 2003:328).

a. Kai nimi wiupui-gga yaa.

NEG person buckberry-have there

'We have no buckberries this time.' (dialogue, MS, BP23-1-t1, 3) 
b. Su=natizuabi kai togi i=ma-nimma.

DEF.NOM=medicine NEG correct 1 SG.ACC=IP.hand-feel

'The medicine doesn't make me feel quite right.' (elicitation, Thornes 2003:328)

Assuming that negation adjoins either to $\mathrm{TP}$ or to $\mathrm{vP}$ - the two positions where negation is attested cross-linguistically (Laka 1990:9-85) — when it adjoins to vP, it should be possible inside nominalizations. This is indeed the case:
a. I=dua kai tika-na pisa kamma-di.
'What my son didn't eat is good tasting.' (elicitation, MS, BP43-2-s, 1)
$\begin{array}{lll}\text { b. } & \text { Niq } \quad \text { ka=kai } \quad \text { mia-di sita-ggi-ti. } \\ \text { 1SG.NOM DEF.ACC=NEG go-NMLZ bad-APPL-TNS }\end{array}$
'I am angry at the one who won't leave.' (elicitation, EM, BP37-1-s, 24)

I will return to the question of whether high negation is possible inside nominalizations shortly.

Finally, left-edge adverbs can appear inside both types of nominalization. This includes $p \dot{t} d \dot{t}$ 'just' (15a-b) and the manner adverb obida 'slowly' (16a-b).
a. I=bia
pidi saa-na pisa kamma.
1SG.GEN=mother just cook-NMLZ good taste
'What my mother just cooked tastes good.' (elicitation, EM, BP34-4-s, 14)
b. $\quad$ Su=pidi $\quad$ kati-di oo ya'i-hu.
DEF.NOM=just sit-NMLZ there die-PUNC
'The one who just sat down died there.' (elicitation, EM, BP35-2-s, 5)
a. I=bia
obida saa-na nị tika.
1SG.GEN=mother slowly cook-NMLZ 1sG.NOM eat
'I ate what my mother cooked slowly.' (elicitation, EM, BP37-1-s, 21)
b. Niq ka=obida mia-di nagi-gga'a.
1SG.NOM DEF.ACC=slow go-NMLZ chase-MOT
'I will chase the one who is running away slowly.' (elicitation, MS, BP34-4-s, 16)
Assuming that $p \dot{t} d \dot{i}$ 'just' and manner adverbs like obida 'slowly' adjoin to vP, then the presence of these left-edge elements is expected if these nominalizations embed a vP. ${ }^{6}$

\footnotetext{
${ }^{6}$ Aspectual morphology is also possible inside deverbal nominalizations in Northern Paiute. In (ii-ii), this is the so-called punctual suffix $-h u$, which encodes that the event described is 'bounded, that is, whether or not either the initial or terminal endpoint is expressed or understood' (Thornes 2003:407).

(i) Nï timi-hu ka=i=naa'a ka=tihidda pi-ma-mma patsa-hu-na. 1SG.NOM buy-PUNC DEF.ACC=1SG.GEN=father DEF.ACC=deer PRO-LOC-LOC kill.SG-PUNC-NMLZ 'I bought what my father killed the deer with.' (elicitation, MS, BP34-3-s, 48)

(ii) Usu i=doogga wati-hu-di wadzi-mia. DEM.NOM 1SG.GEN=dog shoot-PUNC-NMLZ hide-run

'The one who shot my dog ran away.' (elicitation, EM, BP34-3-s, 46)
}

If aspectual information is generally conveyed by functional heads located roughly between $\mathrm{v}$ and $\mathrm{T}$ (Cinque 1999), 


\subsubsection{The nominalizers do not embed a CP}

But how do we know $-n a$ and $-d \dot{t}$ do not embed a verbal constituent larger than vP? Northern Paiute has an inventory of clitics expressing various modal categories that occur in second position following the first major sentence constituent (Thornes 2003:336-341). The modal clitic =sakwa 'should, might', for instance, can occur after the subject (17a), a fronted direct object (17b), or a sentence-initial adverb (17c).
a. Ii $=$ sakwa pida.
2SG.NOM=MOD start.fire
'You should start the fire.' (elicitation, EM, BP33-5-s, 47)
b. Himma=sakwa tammi madabbui.
thing=MOD 1PL.INCL make
'We might make something.' (elicitation, EM, BP34-2-s, 17)
c. Mu'a=sakwa tammi tiba'a hani-ga-kwí.
tomorrow=MOD 1PL.INCL pinenut do-MOT-PROSP
'Tomorrow, we are going to go get pinenuts.' (elicitation, EM, BP33-5-s, 51)

The modal clitic =sakwa 'must, could' is ungrammatical when it is the second element in a nominalization with $-n a$, as shown in (19). It is likewise ungrammatical in a nominalization with $-d \dot{t}$, regardless whether it attaches to the determiner (19a) or some other host, such as the direct object tiba 'pinenut' in (19b).

* $\mathrm{Nit} \quad \mathrm{ka}=\mathrm{i}=$ dua=sakwa
1SG.NOM DEF.ACC=1SG.GEN=son=MOD eat-NMLZ outside throw

Intended: 'I threw out what my son should have eaten.' (elicitation, EM, BP37-1, 58:14)
a. * Su=sakwa na-gwitama-di wadzi-mia-hu.
DEF.NOM=MOD PASS-lock-NMLZ hide-go-PUNC

Intended: 'The one who should be locked up ran away.' (elicitation, MS, BP34-4, 56:58)

b. * Su=tiba=sakwa hani-di oo siggwi kati.

DEF.NOM=1PL.INCL=MOD do-NMLZ there just sit

Intended: 'The one who should be cleaning pinenuts is just sitting over there.' (elicitation, EM, BP37-1, 49:14)

Assuming that modal clitics occupy $\mathrm{C}$ - like the highest auxiliary or main verb in verb-second Germanic languages (Koster 1975, among others) - the nominalizations created by -na and $-d \dot{t}$ cannot embed a verbal constituent as large as $\mathrm{CP}$.

\subsubsection{The nominalizers do not embed a TP}

There is also evidence that the nominalizers in Northern Paiute do not embed a TP. The Thead itself is not obviously realized overtly in the language by auxiliaries or markers of tense and finiteness. ${ }^{7}$

we might actually want to say that the nominalizers $-n a$ and $-d \dot{i}$ embed a slightly larger verbal projection below $\mathrm{T}$. For our purposes, though, the simpler assumption that these nominalizers embed vP suffices.

${ }^{7}$ The so-called irrealis suffix $-d u a$ in Northern Paiute is unable to occur inside nominalizations with -na and -di: 
But recall from (13a) above that negation in Northern Paiute can occur to the left of the subject in sentence-initial position. Assuming that it is adjoined to TP, nominalizations with -na do not embed a TP since they cannot contain high negation:

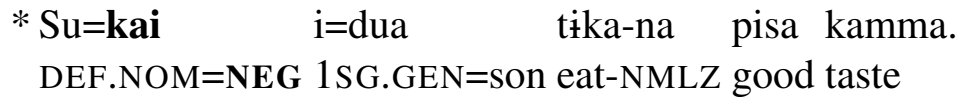

Intended: 'What my son didn't eat tastes good.' (elicitation, MS, BP43-2, 2:36)

Unfortunately, negation is not as useful for probing the structure of nominalizations with - $d \dot{t}$ since they do not contain a subject- see $\S 4$.

More indirectly, though, we can see that neither type of nominalization in Northern Paiute embeds a TP, since they do not contain nominative case. In a regular clause, the subject receives nominative case, which in (21) is realized on the first-person singular nominative pronoun $n \ddot{i t}$ ' $I$ '.

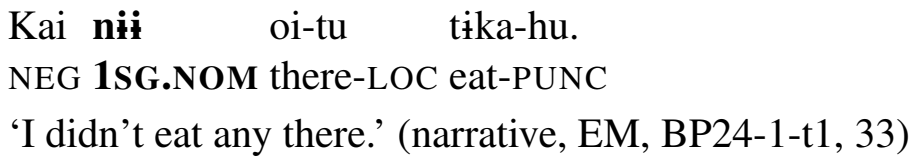

In nominalizations with -na, though, the highest argument of the embedded verb receives - not nominative case - but genitive case, like the possessor in a possessive description. Both the external argument of the -na nominalization in (22) and the possessor of the possessive description in (23) are realized as the genitive proclitic pronoun $i=$ 'my'.

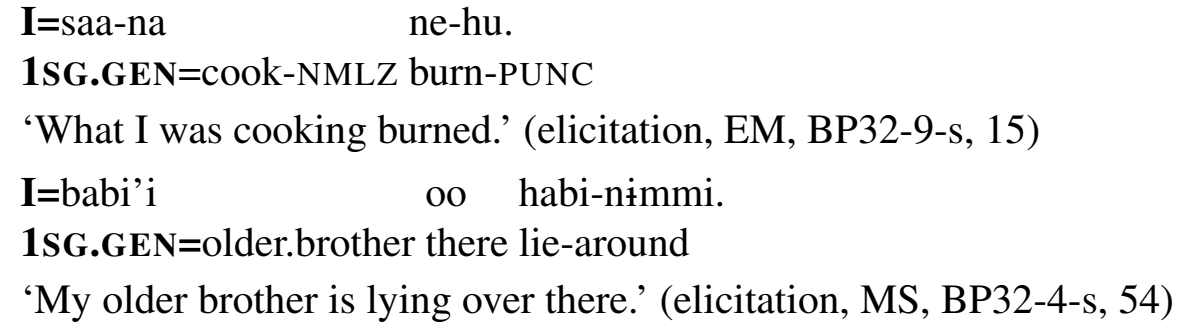

Nominalizations with $-d \dot{t}$, too, do not contain nominative case. It is ungrammatical for the highest argument of the verb to be realized overtly as the first singular nominative pronoun $n i \dot{t}$ ' $\mathrm{I}$ ' in (24).

$$
\begin{aligned}
& \text { * Su=mogo'ni nii } \quad \text { na-dika-di } \quad \text { natiina-hu. } \\
& \text { DEF.NOM=woman 1sG.NOM PASS-eat-NMLZ take.away-PUNC }
\end{aligned}
$$

Intended: 'The woman took away my food.' (elicitation, EM, BP43-2, 13:13)

Of course, as I will show later in $\$ 2.4$, nominalizations with $-d i$ are not able to realize the highest argument of the verb overtly at all.

\footnotetext{
(i) $* \mathrm{Nii} \quad \mathrm{ka}=$ nana patsa-dua-na timi-hu.

1SG.NOM DEF.ACC=man kill.SG-IRR-NMLZ buy-PUNC

Intended: 'I bought the one that the man will kill.' (elicitation, EM, BP43-2, 9:34)

(ii) $*$ I=kutsu kwati-dua-di kwana'a nobi-ka-'yu.

1SG.GEN=cow shoot-IRR-NMLZ far house-have-NOM

Intended: 'The one who will shoot my cow lives far away.' (elicitation, EM, BP32-8, 59:16)
}

Thornes (2003:406) writes that its function '...falls under the broad functional domain of irrealis. That is, the event is "hypothetical, possible, and uncertain" (Givón 1984) [original emphasis].' If the irrealis suffix realizes T, it would provide more direct evidence that nominalizations in Northern Paiute do not embed TP. 


\subsection{The nominal structure of deverbal nominalizations}

If the nominalizers $-n a$ and $-d \dot{t}$ are realizations of the Poss head when it takes a vP complement, then any nominal functional categories above Poss in the extended nominal projection should be able occur outside a nominalization.

Following much recent work, I assume that Poss is located below $\mathrm{D}$ (eterminer) and above $\mathrm{N}$ in the extended verbal projection:

$$
\text { D }>\text { Poss }>\mathrm{N}
$$

In this hierarchy, Poss is treated as the analogue of T(ense) in the verbal domain (Szabolcsi 1983, 1987, 1994, Cardinaletti 1998, Alexiadou et al. 2007:556-575). This is clearly inspired by the DP Hypothesis, proposed by Abney (1987:54-85) and Horrocks and Stavrou (1987) for English. But rather than being the nominal correlate of T, D is treated as the nominal correlate of $\mathrm{C}$. This parallelism between DP and CP was in some ways foreseen by Horrocks and Stavrou, who analyze Spec-DP in Greek as an A'-position that functions as an escape-hatch for movement, just like SpecCP (see also Szabolcsi 1983, 1989 on Hungarian).

The position of Poss below $\mathrm{D}$ is needed to account for the location of possessors in a number of different languages, including Northern Paiute. For instance, in Italian, weak and clitic possessive pronouns receive case in Spec-PossP, with the weak possessive pronouns surfacing there (the clitics subsequently move even higher to D) (Cardinaletti 1998). In Hungarian, both pronominal and nonpronominal possessors can occur below the determiner in Spec-PossP (Szabolcsi 1983, 1987, 1994). In Northern Paiute, too, possessors can surface below D in Spec-PossP. Full DP possessors, as in (26a), and genitive strong pronouns, as in (26b), occur to the right of a determiner.

$$
\begin{array}{ll}
\text { a. Su=nana tua wadzi-mia. } \\
\text { DEF.NOM=man son hide-go } \\
\text { 'The man's son ran away.' (elicitation, MS, BP32-3-s, 6) } \\
\text { b. Su=nana ka=nika puggu patsa-hu. } \\
\text { DEF.NOM=man DEF.ACC=1SG.GEN horse kill.SG-PUNC } \\
\text { 'The man killed MY horse.' (elicitation, EM, BP32-3-s, 23) }
\end{array}
$$

As predicted, deverbal nominalizations in Northern Paiute can be embedded under D, as we have already seen. The nominalizations in (27) and (28a), repeated from (8a) and (9a) above, both occur with overt determiners. It does not matter in the nominalization whether the possessor is a full DP, as in (28a), or a strong genitive pronoun, as in (28b).

$$
\begin{aligned}
& \text { Su=kutsu patsa-di mia-hu. } \\
& \text { DEF.NOM=cow kill.sG-NMLZ go-PUNC }
\end{aligned}
$$

'The cow killer left.' (elicitation, EM, BP37-1-s, 16)

$$
\begin{aligned}
& \text { a. Su=pa'mogo ka=nana ti-patsa-na-gguba kati. } \\
& \text { DEF.NOM=frog DEF.ACC=man NSP-kill.SG-NMLZ-LOC sit.DUR } \\
& \text { 'The frog is sitting on the man's kill.' (elicitation, EM, BP32-7-s, 14) } \\
& \text { b. Su=naatsi'i ka=nika saa-na kai pisapi. } \\
& \text { DEF.NOM=boy DEF.ACC=1sG.GEN cook-NMLZ NEG like.DUR } \\
& \text { 'The boy doesn't like the thing I cooked.' (elicitation, EM, BP37-2-s, 13) }
\end{aligned}
$$


There is another nominal category that is found in Northern Paiute but that is not included in the hierarchy in (25): number. Some nouns can be marked for plural number with the suffix -mi, e.g. tua 'son' tuami 'sons, children' (Thornes 2003:100). For a small number of nouns - mostly ones referring to humans - plural number can be marked through reduplication, e.g. moko' $n i$ 'woman' $\sim$ mommoko'ni 'women', or suppletion, e.g. siadimi 'young woman' $\sim$ sisita' 'young women' (Thornes 2003:103). Neither of these instantiations of number tells us much about the hierarchical position of the nominalizers, because they are realized on the noun itself.

There is, however, another more productive realization of plural number, the prenominal proclitic $m \dot{t}=$. Thornes $(2003: 131)$ analyzes the proclitic as a definite determiner, but I do not adopt this analysis since $m \dot{t}=$ is not in complementary distribution with other definite determiners. As shown in (29), it occurs immediately below the accusative definite determiner $k a=$.

$$
\begin{aligned}
& \text { Su=hudziba ka=mi=naa'atsi'i-gguba-ggwe yodzi-huka. } \\
& \text { DEF.NOM=bird DEF.ACC=PL=boy.PL-LOC-LOC fly-INCH.DUR } \\
& \text { 'The bird flew over the boys.' (elicitation, MS, BP32-4-s, 51) }
\end{aligned}
$$

Instead, I assume that $m \dot{t}=$ is the realization of a Num(ber) head located immediately below D. Nominalizations with $-n a$ and $-d \dot{t}$ can show up embedded under the $m \dot{t}=$ plural marker:

$$
\begin{array}{ll}
\text { a. } & \mathbf{M i}=\mathrm{i}=\text { yadua-na } \\
\mathbf{P L}=1 \text { SG.GEN=talk-NMLZ there sit.PL-NMLZ }
\end{array}
$$

'The people I was talking to are the ones sitting over there.' (elicitation, EM, BP327-s, 27)

b. $\quad \mathrm{Su}=$ nana $\mathrm{ka}=\mathbf{m i}=$ aataa-di $\quad$ yadu'i.

$\mathrm{NOM}=$ man DEF. $\mathrm{ACC}=\mathbf{P L}=$ sit.PL-NMLZ talk.to.DUR

'The man is talking to the sitting people.' (elicitation, EM, BP37-2-s, 7)

Just as we would expect if the nominalizers $-n a$ and $-d \dot{t}$ realize Poss, the nominalizations they create can be embedded both under a determiner (D) and under the plural marker (Num).

\subsection{An obligatory possessor in nominalizations with -na}

While the two nominalizers are similar in many ways, I am proposing that they differ in one important way. While -na projects a specifier to which it assigns genitive case, just as the Poss head does in possessive descriptions, $-d \dot{t}$ does not.

This makes two predications. First, nominalizations with -na should always contain a DP in Spec-PossP. Indeed, when the embedded predicate is a zero-place predicate - such as the weather verb titiggwa 'snow' - an expletive proclitic pronoun $a=$ is obligatory:

$$
\begin{array}{ll}
\mathrm{Ni \dot { }} & *(\mathbf{a}=) \text { ddiłggwa-winni-na punni. } \\
\text { 1SG.NOM } & \text { 4.GEN=snow-STAT-NMLZ see.DUR }
\end{array}
$$

'I see it snowing.' (elicitation, EM, BP37-3, 1:14:26)

Second, since Spec-PossP is the position where possessors get genitive case, the DP that occupies this position in a nominalization with $-n a$ should have the same realization as a possessor. As I show below, this is indeed the case. 


\begin{tabular}{|c|c|c|c|c|c|}
\hline & \multirow[t]{2}{*}{ NOMINATIVE } & \multicolumn{2}{|c|}{ ACCUSATIVE } & \multicolumn{2}{|c|}{ GENITIVE } \\
\hline & & strong & proclitic & strong & proclitic \\
\hline $1 \mathrm{sg}$. & $n \ddot{t} \dot{t}$ & $n i k a$ & $i=$ & niga $(n \dot{t} k a)$ & $i=$ \\
\hline $2 \mathrm{sg}$. & $\ddot{i t}$ & $\dot{t} m i$ & $\dot{t}=$ & $\dot{t} g a(\dot{t} m i)$ & $\dot{t}=$ \\
\hline $3 \mathrm{sg}^{8}{ }^{8}$ & isu, usu, masu & $i k a, u k a$, maka & $u=$ & $\begin{array}{c}\text { iga, uga, maga } \\
(i k a, u k a, \text { maka })\end{array}$ & $u=$ \\
\hline $1 \mathrm{dl}$. & ta & taka $($ ta $)$ & $t a=$ & $\operatorname{tag} a(\operatorname{ta})$ & $t a=$ \\
\hline 1pl. incl. & tammi & tammika (tammi) & $t i=$ & tammiga $($ tammi) & $t i=$ \\
\hline 1pl. excl. & $n \dot{t} m m i$ & nimmika (nimmi) & $n i=, m i=$ & nimmiga $($ nimmi) & $n i=, m i=$ \\
\hline 2/3pl. & $\dot{\boldsymbol{t} m \dot{t}}$ & $u m \dot{t}$ & $m \dot{t}=$ & umiga (umí) & $m \dot{t}=$ \\
\hline 4 & & & $a=$ & & $a=$ \\
\hline
\end{tabular}

Table 1: Nominative, accusative, and genitive pronouns in Northern Paiute (Thornes 2003:155169); parenthetical forms from the Mono Lake dialect

\subsubsection{Genitive pronouns}

When the possessor in a possessive description is a full DP, it bears no special morphology. In (26a) above, the possessor DP nana 'the man' is a bare noun. When the possessor is a pronoun, however, it receives a special realization. As shown in Table 1, there are two series of genitive pronouns in Northern Paiute, alongside the language's nominative and accusative pronouns. The genitive strong pronouns are morphologically independent and are used when the possessor is focused, as in (32a), repeated from (26b) above. Otherwise, the genitive proclitic pronouns are used, which select the noun heading the possessive description as their host, as in (32b).

$$
\begin{aligned}
& \text { a. Su=nana ka=nika } \quad \text { puggu patsa-hu. } \\
& \text { DEF.NOM=man DEF.ACC=1sG.GEN horse kill.SG-PUNC } \\
& \text { 'The man killed MY horse.' (elicitation, EM, BP32-3-s, 23) } \\
& \text { b. Su=nana i=buggu patsa-hu. } \\
& \text { DEF.NOM=man 1sG.GEN=horse kill.SG-PUNC } \\
& \text { 'The man killed my horse.' (elicitation, EM, BP32-3-s, 24) }
\end{aligned}
$$

As an aside, observe that while the strong pronouns can cooccur with a determiner (32a), the proclitic pronouns are in complementary distribution with the determiner (32b). This is not an uncommon pattern crosslinguistically. To derive the same complementarity for genitive clitic pronouns in Italian, Cardinaletti (1998:17) proposes that they receive case in Spec-PossP but then undergo head movement to D. Assuming that head movement is substitution, if genitive proclitic pronouns in Northern Paiute raise to D, then they will be in complementary distribution with determiners. ${ }^{9}$ They will occupy D instead of an overt determiner. (Ultimately, though, the genitive proclitic pronouns must be realized with the noun heading the possessive description as their host.)

In nominalizations with - na the highest argument of the verb can be realized as a genitive pronoun - either a strong pronoun or a proclitic, as shown in (33a-b).

\footnotetext{
${ }^{8}$ The third-person singular pronouns are simply demonstrative pronouns: proximate $i$-, distal $u$-, and topical $m a-$.

${ }^{9}$ See van Riemsdijk 1998 for discussion of head movement as substitution vs. adjunction.
} 


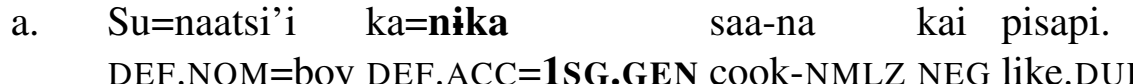

'The boy doesn't like the thing I cooked.' (elicitation, EM, BP37-2-s, 13)

b. I=saa-na ne-hu.

1SG.GEN=cook-NMLZ burn-PUNC

'What I was cooking burned.' (elicitation, EM, BP32-9-s, 15)

Note that no other case realization is possible for the highest argument of the verb. Specifically, it cannot receive nominative case — the canonical case realization for subjects - as shown in (34).

* Nii saa-na ne-hu.

1SG.NOM cook-NMLZ burn-PUNC

Intended: 'What I was cooking burned.' (elicitation, EM, BP43-2, 11:14)

But how do we know that these arguments are not being assigned accusative case? As Table 1 shows, the proclitic pronouns are identical in both the genitive and accusative cases. And, in the Mono Lake dialect of Northern Paiute — on which I conduct fieldwork and from which most of my data comes - the distinction between the accusative and genitive pronouns has been neutralized completely in both the proclitic and strong pronoun series. Unfortunately, in the resources available to me on other varieties of Northern Paiute (Liljeblad 1966, Snapp et al. 1982, Thornes 2003), there are no attested examples of a nominalization with -na where the highest argument is a strong pronoun. From the examples in (33-34), all we can conclude, then, is that there is no nominative case inside these nominalizations, and that it is POSSIBLE that they contain a possessor.

Luckily, however, all varieties of Northern Paiute have a genitive reflexive anaphor $t \dot{i}=$, which Thornes (2003:175) calls ' $[\mathrm{t}] \mathrm{he}$ most important distinction between the possessor proclitics and transitive object proclitics...' In (35), the anaphor is the possessor of the noun toogga 'dog'. Crucially, it is ungrammatical in direct object position, as shown in (36).

$\mathrm{Su}=$ naatsi'i ${ }_{1} \quad$ bino'o $\mathrm{ka}=\mathbf{t} \mathbf{i}={ }_{1}$ ddoogga haan; kuyaa $\mathrm{o}=$ dda-yaggwine'e-hu

DEF.NOM=boy PTC DEF.ACC=REFL=dog scold far 3SG.ACC=IP.foot-kick-PUNC

tabbu'a.

look.like

'The boy ${ }_{1}$ is scolding his ${ }_{1}$ dog, and then he kicks him to go away.' (prompted narrative, MS, BP24-1-t3, 41)

$* \mathrm{Su}=$ naatsi' $i_{1} \quad \mathbf{t} \mathbf{i}={ }_{1}$ bbuni.

DEF.ACC $=$ boy $\mathbf{R E F L}=$ see

Intended: 'The boy 1 sees himself 1 .' (elicitation, EM, BP37-2, 36:35)

This anaphor, which only functions as a possessor, can be the highest argument of a nominalization with -na:

Oo uu ka=ti=1 ${ }_{1}$ í-patsa-na usu idza $_{1}$ pï owi manai

there thusly DEF.ACC $=\mathbf{R E F L}=$ NSP-kill.SG-NMLZ DEM.NOM coyote $3 \mathrm{SG}$ there do

čaisi u-ma koggwi-u.

then that-LOC take.away-PUNC

'So it was of his ${ }_{1}$ kill, that Coyote $_{1}$, he took it over then and took it away.' (narrative, Thornes 2003:484) 
In (37), the agent of the nominalized verb patsa 'kill (sg.)', projected as the genitive reflexive anaphor, corefers with the subject DP usu idza 'that Coyote'.

\subsubsection{Case on adjectives}

The case realization of adjectives shows more indirectly that nominalizations with -na contain a possessor. When a possessor contains an adjective, it receives the case-either nominative or accusative — of the ENTIRE possessive description:
a. [DP [DP Miitsi-'yu nana $]$ dua $]$ habi-hu. short-NOM man son lie-PUNC
'The short man's son fell down.' (elicitation, EM, BP32-3-s, 18)
b. $\quad \mathrm{Nii} \quad[\mathrm{DP} \mathrm{ka}=[\mathrm{DP}$ miitsi-ggu nana $]$ toogga $]$ pisapi.
1SG.NOM DEF.ACC $=$ short-ACC man dog like.DUR
'I like the short man's dog.' (elicitation, EM, BP37-2-s, 18)

The adjective miitsi 'short' gets the nominative case suffix -'yu in a possessive description that is the subject (38a), and the accusative case suffix -ggu in a possessive description that is the direct object (38b). When the highest argument in a nominalization with - na contains an adjective, it exhibits the same pattern of case marking:
a. $\quad[$ DP $S u=[$ DP miitsi-'yu nana $]$ saa-na $]$ pisa kamma.
DEF.NOM=short-NOM man cook-NMLZ good taste
'The short man's cooking tastes good.' (elicitation, EM, BP37-2-s, 19)
b. $\mathrm{Niq} \quad[\mathrm{DP} \mathrm{ka}=[\mathrm{DP}$ waha-ggu momoko'ni $]$ saa-na $]$ pisapi.
1SG.NOM DEF.ACC=two-ACC women cook-NMLZ like.DUR
'I like the two women's cooking.' (elicitation, EM, BP32-8-s, 9)

The adjective waha 'two' is realized with nominative case in (39a) when it modifies the highest argument of a nominalization in subject position, and it is realized with accusative case in (39b) when it modifies the highest argument of a nominalization in direct object position.

As a reviewer points out, this pattern of case concord is somewhat unusual, since the adjective does not agree with the closest case-bearing head. ${ }^{10}$ Assuming that DPs get case by valuing a case feature on $\mathrm{D}$, when an adjective is contained within a possessor, the closest $\mathrm{D}$ that can value the adjective's own case feature should be the one that heads the possessor DP. But as we have seen, an adjective contained within the possessor does not agree in genitive case:

\footnotetext{
${ }^{10}$ This is reminiscent of the inalieable possession construction in Korean, in which the possessor gets the same case marking — whether nominative, accusative, or dative — as the entire possessive description (Mailing and Kim 1992). I leave the exploration of possible parallels for future work.
} 


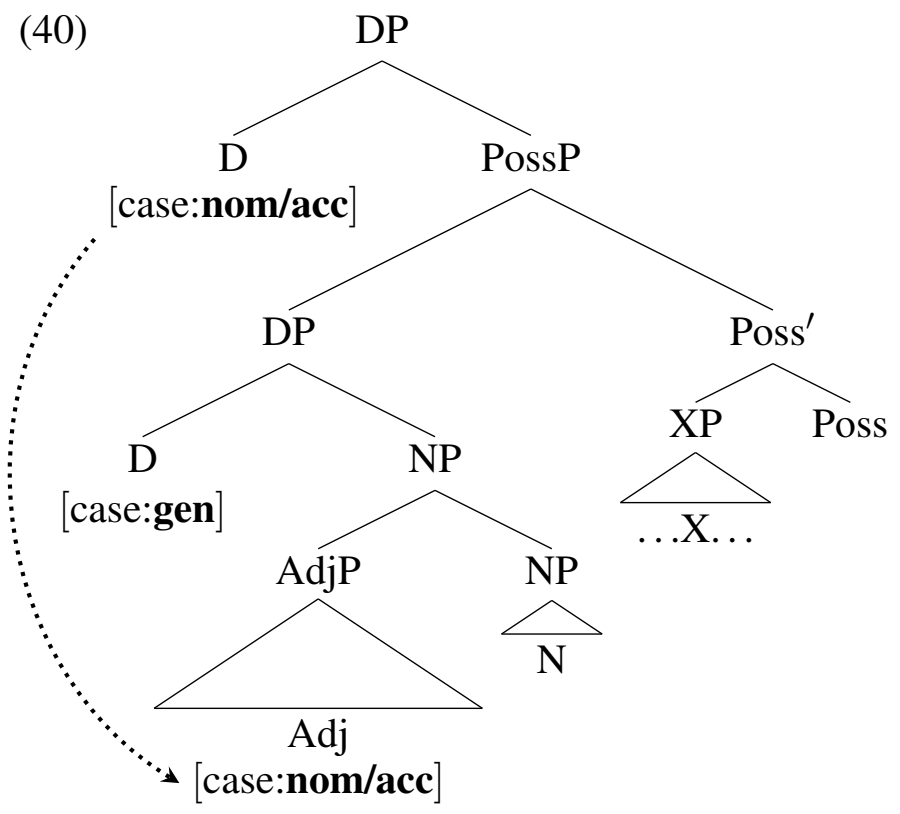

I suspect that this pattern might arise because adjectives are formally deficient in Northern Paiute. Say that the case feature on an adjective can only have certain values. Specifically, it can be valued as either nominative or accusative, but not genitive. When an adjective occurs inside a possessor, then, the closest head bearing a case feature that it can agree with will not be the D heading the possessor DP. Rather, it will be the D heading the entire possessive description.

\subsubsection{Possessor extraction and pied-piping}

Possessors in Northern Paiute do not obey the Left Branch Condition. They can be extracted through obligatory wh-movement to sentence-initial position, as in (41a). Wh-possessors can also optionally pied-pipe the rest of the possessive description along with them, as shown in (41b).
a. Haga $_{1}$
$\left[\mathrm{DP}_{1}\right.$ kaadzi $]$ pisapi?
who.GEN 2SG.NOM car like.DUR
'Whose car do you like?' (elicitation, EM, BP33-5-s, 19)
b. $\quad[\text { DP Haga kaadzi }]_{1}$ iq $\quad t_{1}$ pisapi?
who.GEN car 2SG.NOM like.DUR

'Whose car do you like?' (elicitation, EM, BP33-5-s, 18)

The highest argument in nominalizations with -na exhibits the same pattern. When it is a whphrase, it can be extracted by itself (42a) or the rest of the nominalization can raise with it to sentence-initial position (42b).
a. Haga ${ }_{1} \quad \mathrm{su}=$ nana $\quad\left[\mathrm{DP}_{1} \mathrm{t}_{1}\right.$ ti-batsa-na $] \quad$ tidiha-huka?
who.GEN DEF.NOM=man NSP-kill-NMLZ steal-INCH.DUR
'Whose kill did the man steal?' (elicitation, EM, BP33-5-s, 15)
b. [DP Haga ti-batsa-na $]_{1}$ su=nana $\mathrm{t}_{1}$ wadzi-hani-huka?
who.GEN NSP-kill-NMLZ DEF.NOM=man hide-do-INCH.DUR
'Whose kill did the man take away?' (elicitation, EM, BP33-5-s, 13)


This optional pied-piping of nominalizations is expected if the wh-phrase in (42a-b) is a possessor.

\subsection{No possessor in nominalizations with $-d i$}

If $-d \dot{i}$ realizes the Poss head when it does not project a specifier, then the nominalizations it creates should NEVER contain a possessor. Indeed, adding a possessor to the nominalization in (43a) is ungrammatical, regardless of whether it is a genitive pronoun (43b), a nominative pronoun (43c) or a full DP (43d).
a. Su=mogo'ni ka=na-dika-di natiina-hu.
DEF.NOM=woman DEF.ACC=PASS-eat-NMLZ take.away-PUNC
'The woman took away the food.' (elicitation, MS, BP37-2-s, 29)
b. * Su=mogo'ni i=na-dika-di natitna-hu.
DEF.NOM=woman 1SG.GEN=PASS-eat-NMLZ take.away-PUNC
Intended: 'The woman took away my food.' (elicitation, EM, BP37-2, 57:04)
c. * Su=mogo'ni nii na-dika-di natiina-hu.
DEF.NOM=woman 1SG.NOM PASS-eat-NMLZ take.away-PUNC
Intended: 'The woman took away my food.' (elicitation, EM, BP43-2, 13:13)
d. * Su=mogo'ni ka=nana na-dika-di natiina-hu.
DEF.NOM=woman DEF.ACC=man PASS-eat-NMLZ take.away-PUNC
Intended: 'The woman took away the man's food.' (elicitation, EM, BP37-2, $1: 01: 17)$

It does not make a difference if the nominalization describes an event as opposed to an individual. The nominalization in (44a) becomes ungrammatical when a genitive proclitic pronoun is added, as shown in (44b).
a. Nï ka=tiiggwa-di punni.
1SG.NOM DEF.ACC=snow-NMLZ see.DUR
'I see it snowing.' (elicitation, EM, BP37-2-s, 32)
b. * Niq a=ddiiggwa-di punni.
1SG.NOM 4.GEN=snow-NMLZ see.DUR
Intended: 'I see it snowing.' (elicitation, EM, BP37-2, 1:04:03)

Unlike the parallel nominalization with -na in (31), the nominalization with - $d \dot{t}$ in (44b) is ungrammatical because it contains a possessor.

I have argued that the deverbal nominalizers - na and $-d \dot{t}$ realize Poss - the nominal functional head that canonically assigns case to possessors - when it takes a vP complement. This accounts for the noun-like external distribution of the nominalizations they create, as well as their verblike internal structure. In addition, I argued that while -na projects a specifier to which it assigns genitive case, $-d i$ is defective and does not project a specifier position at all. With a syntax in hand for the two types of deverbal nominalization in Northern Paiute, I now go on to show how they are able to describe both events and individuals. 


\section{The interpretation of nominalizations with $-n a$}

Some basic examples of nominalizations with -na are presented again below. They can describe an event $(45 \mathrm{a}-\mathrm{c})$ or an individual participating in an event $(46 \mathrm{a}-\mathrm{b})$.
a. $\quad \mathrm{Su}=\mathrm{nana}$
ka=toogga
idzi'i.
DEF.NOM=man DEF.ACC=dog kill.SG-NMLZ yesterday

'The man's killing the dog happened yesterday.' (elicitation, MS, BP32-4-s, 29)

b. $\mathrm{Niq}$ ka=Grace hubia-du-na pisapi.

1 SG.NOM DEF.ACC=Grace song-make-NMLZ like.DUR

'I like Grace's singing.' (elicitation, EM, BP32-9-s, 7)

c. Nii ka=mogo'ni tiba'a saa-na ikwi.

1SG.NOM DEF.ACC=woman pinenut cook-NMLZ smell

'I smell the woman cooking pinenuts.' (elicitation, EM, BP32-7-s, 35)
a. Niq ka=i=naa'a saa-na tika.
1SG.NOM DEF.ACC=1SG.GEN=father cook-NMLZ eat
'I ate the thing that my father cooked.' (elicitation, EM, BP37-2-s, 35)
b. Pi-kuba i=ggati-na ni் timi-kwi.
PRO-LOC 2SG.GEN=sit-NMLZ 1SG.NOM buy-PROSP
'I am going to buy the one you are sitting on.' (elicitation, MS, BP37-1-s, 15)

The nominalizations in (46a-b) clearly refer to individuals since the matrix verbs express predicates that can only hold of individuals. The event nominalizations in $(45 \mathrm{a}-\mathrm{c})$ deserve a bit more scrutiny.

There are two main pieces of evidence that they do, in fact, describe an event and not just an individual. First, the sentence in (45c) expresses the perception of an event through smell. This event is described by the nominalization in direct object position, immediately to the left of $i k w i$ 'smell'. ${ }^{11}$ This is truth-conditionally distinct from simply perceiving one of the individuals participating in the event. If the speaker perceives an event of the woman cooking pinenuts through smell, she does not necessarily perceive either the agent or the patient.

Second, the nominalizer -na can apply to zero-place predicates, such as the weather verbs pauma 'rain' and tïggwa 'snow' in $(47 \mathrm{a}-\mathrm{b})$.

\footnotetext{
${ }^{11}$ It is difficult to tell whether the nominalization in (45c) also receives accusative case because the definite determiner could be parsed with the possessor mogo'ni. As a consequence, a reviewer wonders whether the possessor mogo'ni 'woman' itself is not the direct object of $i k w i$ 'smell', since perception verbs are often raising-to-object predicates. But when the possessor is realized as a genitive proclitic pronoun, it cliticizes to the nominalized verb, as shown in (i), and not to the perception verb.

(i) Nit ka=toogga i=ggwiba-na naka.
1SG.NOM DEF.ACC=dog 2SG.GEN=hit-NMLZ hear

'I hear you hitting the dog.' (elicitation, MS, BP37-1-s, 9)

Even if (45c) were a raising-to-object construction, that would tell us nothing about the semantics of nominalizations with -na.
} 
a. Niq a=bbauma-winni-na naka.
1SG.NOM 4.GEN=rain-STAT-NMLZ hear

'I hear it raining.' (elicitation, MS, BP37-1-s, 6)

b. $\quad \mathrm{Su}=$ nana $\quad$ =ddiggwa-winni-na-ggwe nika.

DEF.NOM=man 4.GEN=snow-STAT-NMLZ-LOC dance

'The man is dancing when its snowing.' (elicitation, EM, BP43-2, 15:54)

Since zero-place predicates do not take any individual-type arguments, the nominalizations in (47a-b) must describe events. In (47a), the speaker perceives an event of raining through hearing, and in (47b), the man is dancing during an event of snowing. (The postposition -ggwe can express a relation of temporal overlap in addition to its locatival meaning.)

Whether they describe an event or an individual, nominalizations with -na have the same basic structure, shown schematically in (48). The nominalizer overtly realizes Poss when it takes a vP complement, and it projects a specifier position to which it assigns genitive case.

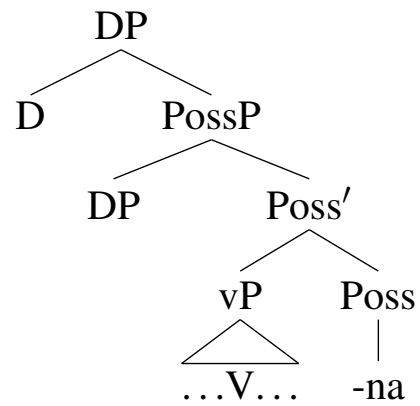

Before getting to the interpretation of nominalizations with -na, I start by showing in $\S 3.1$ that the possessor is always interpreted as an argument of the verb. Consequently, I propose that it originates inside the embedded vP and raises to Spec-PossP to get case. Moving on, then, to the event interpretation, I demonstrate in $\$ 3.2$ that it comes for free, in a manner of speaking, when all of the embedded verb's individual-type arguments are saturated. The individual interpretation, then, arises, I argue in $\S 3.3$, as a special case, when one of the verb's arguments is saturated by a resumptive pronoun. Because Northern Paiute has operators that can abstract over the variable contributed by these resumptive pronouns, nominalizations created by -na describe an individual. In $\$ 3.4$, I explore the properties of these resumptive pronouns, showing why nominalizations with -na only describe individuals that are NOT the highest argument of the verb.

\subsection{The possessor in deverbal nominalizations}

The possessor bears the theta role of the highest argument of the verb. For instance, in (49), repeated from (45a) above, the possessor is the agent of the transitive verb saa 'cook'.

$$
\begin{aligned}
& \text { Nì ka=mogo'ni tiba'a saa-na ikwi. } \\
& \text { 1SG.NOM DEF.ACC=woman pinenut cook-NMLZ smell }
\end{aligned}
$$

'I smell the woman cooking pinenuts.' (elicitation, EM, BP32-7-s, 35)

This interpretation is obligatory. In the context in (50), where the possessor $i=n a a$ ' $a$ 'my father' does not satisfy the agent entailments of the transitive verb patsa 'kill (sg.)', the sentence is infelicitous. 
[My father was driving along when he sees a dead deer along the side of the road. He picks it up and brings it home.]
\# Mu'a tammi i=naa'a ti-batsa-na tika-kwi.
tomorrow 1PL.INCL 1SG.GEN=father NSP-kill-NMLZ eat-PROSP

'Tomorrow we are going to eat what my father killed.' (elicitation, EM, BP33-5, 44:59)

[EM: “That wasn't true...He just telling lie, I guess. Just fooling them or something."]

The native speaker reported that the sentence is not true in the context given, because the speaker's father is not the agent of the killing event. The deer is already dead when he finds it.

This property of nominalizations with -na follows straightforwardly if the possessor originates inside the embedded vP as an argument of the verb. The event nominalization in (49), for instance, has the structure in (51).

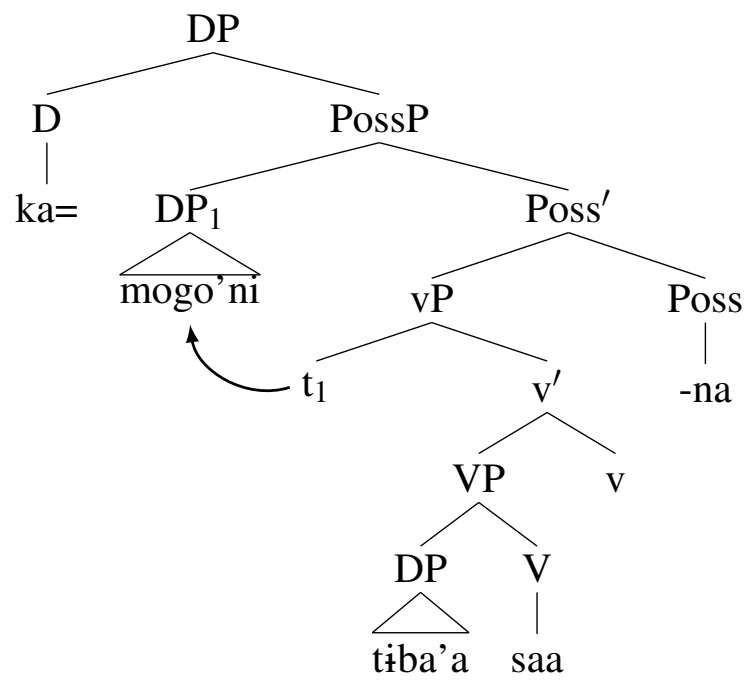

Because saa 'cook' is transitive, $\mathrm{v}$ assigns accusative case to the direct object. The possessor DP mogo'ni 'woman' originates in Spec-vP, where it receives the agent theta role from the embedded verb saa 'cook'. Since the nominalization does not contain $\mathrm{T}$, and hence does not contain nominative case, the possessor can only get case by raising to Spec-PossP, where it is assigned genitive case.

This movement takes place overtly. The possessor in nominalizations with -na occurs to the left of left-edge adverbs:

I=bia obida ka=tiba'a sa'a.

1SG.GEN=mother slowly DEF.ACC=pinenut cook.DUR

'My mother cooked the pinenuts slowly.' (elicitation, EM, BP37-1-s, 20)

$$
\begin{array}{lll}
\text { I=bia obida saa-na nij tika. } \\
\text { 1SG.GEN=mother slowly cook-NMLZ } & 1 \text { sG.NOM eat }
\end{array}
$$

'I ate what my mother cooked slowly.' (elicitation, EM, BP37-1-s, 21)

In a basic SOV sentence like (52), the manner adverb obida 'slowly' occurs to the left of the direct object, at the left edge of the verb phrase. Assuming that manner adverbs adjoin to vP (Pollock 1989:366), the agent of the nominalization in (53) must have raised to Spec-PossP, since it appears to the left of obida 'slowly'. 
While the possessor is the agent in (49), under my account it need only be the HIGHEST argument of the verb. Indeed, when -na embeds an unaccusative or passive verb, the possessor bears a different theta role:

\author{
Su=toogga akwisi'e-na $i=$ masia-hu. \\ DEF.NOM=dog sneeze-NMLZ 1 SG.ACC $=$ scare-PUNC \\ 'The dog's sneezing scared me.' (elicitation, EM, BP33-3-s, 7) \\ I=bia na-bida-ggi-na nai-hu. \\ 1SG.GEN=mother PASS-make.fire-APPL-NMLZ burns-PUNC
}

'The fire built for my mother burned.' (elicitation, EM, BP34-2-s, 43)

In (54), the possessor is the patient of akwisi'e 'sneeze'; in (55), it is the beneficiary $i=b i a$ 'my mother', which is added by the applicative suffix before the predicate is passivized. Since these predicates lack an external argument, accusative case is not assigned by Burzio's Generalization. It is consequently an internal argument of the verb that lacks case and raises to Spec-PossP.

We might wonder, if the highest argument in a deverbal nominalization occupies Spec-PossP, whether it also receives the semantics of a possessor. The possession relation in possessive description is, of course, notoriously variable. The possessor can stand in a variety of superficially different semantic relations to the possessee, determined in part by the noun that heads the possessive description. In (56a), for instance, the possessor Kaabidzi 'Kaabidzi' is interpreted as the spouse of the possessee, because the noun nodikwa 'wife' is inherently relational.

\title{
a. kaabidzi nodikwa Kaabidzi wife
}

'Kaabidzi's wife' (Thornes 2003:145)

b. [My younger brother and sister each have a frog] I=gwana'a pa'mogo isikwidda-di. 1SG.GEN=younger.brother frog be.brown-NMLZ

'My younger brother's frog is brown.' (elicitation, EM, BP34-5, 17:40)

c. [I go out hunting with my father and my younger brother. Only I have a gun. My father and younger brother each see a different deer at the same time.]

$$
\begin{aligned}
& \text { Nii i=naa'a tihidda patsa-hu. } \\
& \text { 1SG.NOM 1sG.GEN=father deer kill.SG-PUNC } \\
& \text { 'I shot my father's deer.' (elicitation, MS, BP37-3, 1:13:46) }
\end{aligned}
$$

For nouns that are inherently nonrelational, the possession relation is context dependent and varies with the context of utterance. In (56b), an ownership relation holds between the speaker's younger brother and the frog, and in (56c), a seeing relation holds between the speaker's father and the deer.

To account for this variability, I assume, following Szabolcsi (1994), that the Poss head itself does not contribute the content of the possession relation. When the possessee is an inherently relational noun, the possessor in Spec-PossP stands in whatever relation is described by the noun itself (or is added by a nominal functional head on par with $\mathrm{v}$ in the verbal domain; Valois 1991:15f., 
Sportiche 1998:216-230, Carstens 2000, Radford 2000, Bowers 2011). ${ }^{12}$ For deverbal nominalizations in Northern Paiute - which are parallel to inherently relational nouns, as the semantic relationship between the possessor and the verb is constant and does not vary - Poss would consequently not add any additional meaning. The possessor receives the theta role of the highest argument of the verb because it starts out inside the vP and then raises to Spec-PossP where it receives case.

If the Poss head in nominalizations with -na obligatorily projects a specifier, but does not itself impose any semantic requirements on it, then it should be possible for that position to be filled by an expletive pronoun. In a normal clause, zero-place predicates, such as the weather verb titggwa 'snow' in (57), do not require an overt subject. But when the same verb is nominalized with -na, as in (58), the expletive $a=$ is obligatory.

Tïggwa-winni.

SnOW-STAT

'It's snowing.' (elicitation, MS, BP32-4-s, 13)

\section{$\mathrm{Nii} \quad *(\mathbf{a}=)$ ddiiggwa-winni-na punni. \\ 1SG.NOM 4.GEN=SnOW-STAT-NMLZ see.DUR}

'I see it snowing.' (elicitation, EM, BP37-3, 1:14:26)

In its contentful use, the fourth-person genitive proclitic pronoun $a=$ identifies an indefinite antecedent. In its expletive use, it fills Spec-PossP and checks genitive case when there is no DP that can raise there.

Before moving on, let me raise the issue of where the context-dependent possession relation comes from with nonrelational nouns. To some degree, we do not have worry about this here, since the possession relation in deverbal nominalizations with - $n a$ is determined entirely by the embedded verb. But as I understand Szabolcsi (p. 197), when the possessee is a nonrelational noun, the context-dependent possession relation is introduced by a process of derivational morphology that takes an inherently nonrelational noun and turns it into a relational noun. A similar idea is found in the semantics literature, where the context-dependent possession relation is introduced through a type-shifting operation that applies to nonrelational nouns (Pustejovsky 1993, Jensen and Vikner 1994, Partee and Borschev 1998). This permits a uniform syntax and semantics for possessor,s both when the possessee is inherently relational and nonrelational, as well as in deverbal nominalizations. ${ }^{13}$

\footnotetext{
${ }^{12}$ Szabolcsi still takes the Poss head to be the formal theta-assigner for the purposes of the Theta Criterion. The content of the theta role assigned to the possessor in Spec-PossP must then somehow be transmitted from the possessee when it is an inherently relational noun. I do not have too much to say here about formal theta role assignment - if it exists at all-except to observe, as Szabolcsi herself does (p. 192f.), that this would require abandoning the assumption that theta roles are always assigned to DPs in their base-merged position (at D-structure), since the possessor originates low and raises to Spec-PossP.

${ }^{13}$ As a reviewer points out, however, such an approach might not be able to derive the contrast between relational and nonrelational nouns when the possessor occurs AFTER the noun in the Norman of-genitive: i.e. a child of John vs. *a firetruck of John (Partee 1997:465, Barker 1995:9). See Partee and Borschev 2002 and Barker 2011 for discussion of precisely this question.
} 


\subsection{The event interpretation}

Since -na projects a specifier position to which it assigns genitive case, all of the embedded verb's individual-type arguments can be saturated, even though there is no nominative case inside the nominalization. The event interpretation of -na follows straightforwardly from this syntax, once some additional assumptions are in place about how verb phrases are interpreted.

Since Davidson 1967, it is frequently assumed that predicates take an event argument in addition to their regular complement of individual-type arguments. It is this event argument that Kratzer (1996) argues holds the verb phrase together semantically. In her neo-Davidsonian event semantics, both $\mathrm{V}$ and $\mathrm{v}$ denote relations between individuals and events. $\mathrm{V}$ relates the internal arguments to an event, and $\mathrm{v}$ relates the external argument to an event. These predicates of events are combined by a rule of Event Identification, which Kratzer defines (p. 122) as follows: ${ }^{14}$

(59) Event Identification

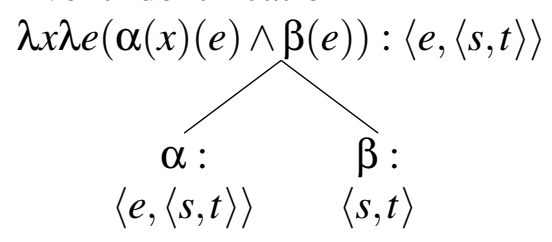

Event Identification takes one function of type $\langle e,\langle s, t\rangle\rangle$ (a function from individuals to functions from events to truth values) and another function of type $\langle s, t\rangle$ (a function from events to truth values) and returns a function of type $\langle e,\langle s, t\rangle\rangle$. In other words, Event Identification combines two predicates of events by abstracting over both of their event arguments.

The semantic composition of the event nominalization in (49) can then proceed as follows:

\footnotetext{
${ }^{14}$ I assume a type-theoretic, compositional, extensional semantics that has, in addition to other rules defined in the text, a rule of Function Application used for interpreting complex constituents (Heim and Kratzer 1998:49). The truth conditions of a sentence, and the contribution that subparts of a sentence make to those truth conditions, are represented by a predicate logic metalanguage with the lambda calculus. Constants are bolded. I use $x, y, z, x^{\prime}, y^{\prime}$, and $z^{\prime}$ as variables over individuals (type $e$ ); $e, e^{\prime}$, and $e^{\prime \prime}$ as variables over events (type $s$ ); and, $p, q$, and $r$ as variables over truth values (type $t$ ). The only higher-order variables are $f, g$, and $h$, which range over functions from either individuals or events to truth values (type $\langle e, t\rangle$ or $\langle s, t\rangle$ ).
} 
(60)

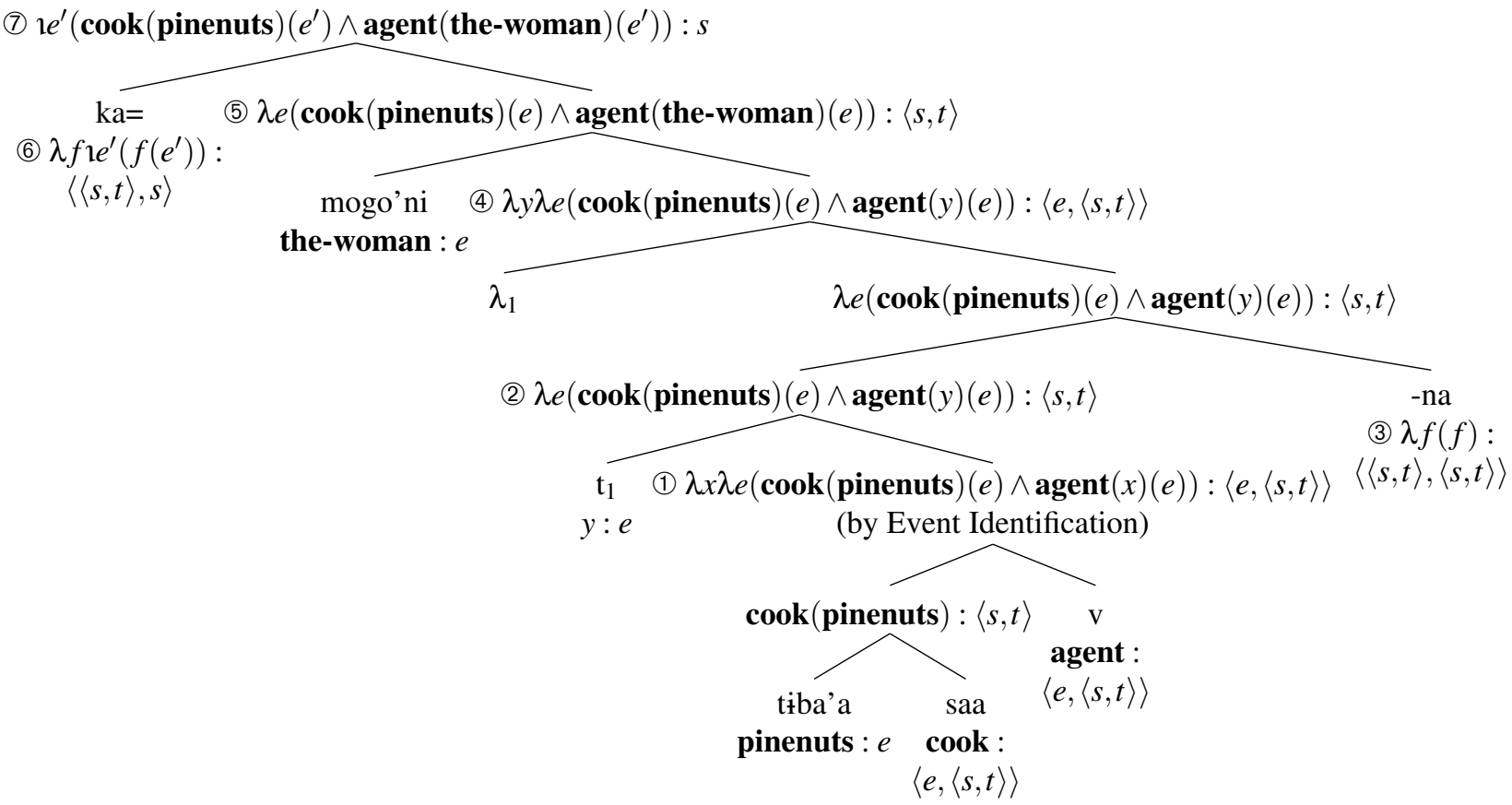

Event Identification combines the predicates of events expressed by the VP and $\mathrm{v}$ to produce a predicate of events whose sole individual argument is the external argument (1). Assuming that traces are interpreted as variables, this argument is saturated by the trace left behind by the DP mogo'ni 'the woman' when it raises to Spec-PossP.

This leaves only the predicate's event argument unsaturated (2)). In clauses, the event variable is existentially bound, so that the sentence has a truth value as its extension. I assume that this operation applies at the vP level through an optional operation of Existential Closure. In a nominalization where all individual-type arguments have been saturated, Existential Closure cannot apply. Existentially binding the event argument would produce a type mismatch, since the embedded vP must still combine with the remainder of the noun phrase. ${ }^{15}$

In particular, the determiner calls for a set of entities as its argument (Barwise and Cooper 1981). I assume that the nominalizer - $n a$ itself denotes the identity function, because it does not contribute anything to the semantics of nominalization (3). It takes a set of entities and returns a set of entities. Following $\lambda$-abstraction over the trace in Spec-vP (4)), the DP in Spec-PossP saturates this argument to produce the set of events of the woman cooking pinenuts (5)). The definite determiner $k a=$ takes this set and returns its unique member (6)). The entire DP refers to the event of the woman cooking pinenuts (7). ${ }^{16}$

The event interpretation arises, then, because the determiner requires a set of entities to apply to. By making an additional case available inside nominalizations, -na permits all of the embedded predicate's individual arguments to project. Once the individual arguments have all been saturated, only the event argument is left open. Consequently, nominalizations with -na describe an event.

\footnotetext{
${ }^{15}$ Alternately, following Hacquard (2010), it might be possible for the event argument to be saturated at the vP level by an event variable. For the nominalization to compose successfully, this event variable would still not be existentially bound. Instead, it would be abstracted over to create a set of events that is able to combine with the determiner. While this would make the composition of event nominalizations more parallel to the composition of individual nominalizations - see $\$ 3.3$ below - I can think of no empirical reason to favor it.

${ }^{16}$ I have assumed a Davidsonian conception of events. But there might be advantages to thinking of events as minimal situations. See Portner 1992:88-145 and Zucchi 1993 for discussion specifically related to nominalization.
} 
This interpretation comes for free, in some sense, because of the syntax of - $n a$ itself. It embeds a $\mathrm{vP}$, and it projects a specifier to which it assigns genitive case.

\subsection{The individual interpretation}

Leaving open the embedded predicate's event argument is not the only way to fashion a set of entities, though. There can also be a gap in an individual argument position, as in (61), repeated from (46) above. When this happens, the nominalization describes an individual.
a. Nii $\mathbf{k a = i = n a a ' a ~}$
saa-na tika.
1SG.NOM DEF.ACC=1SG.GEN=father cook-NMLZ eat
'I ate the thing that my father cooked.' (elicitation, EM, BP37-2-s, 35)
b. $\quad \mathbf{K a}=\mathbf{i}=\mathbf{n a a} \mathbf{a}$
pi-kuba kati-na nï
timi-dua.
DEF.ACC=1SG.GEN=father PRO-LOC sit-NMLZ 1SG.NOM buy-IRR

'I will buy the one my father is sitting on.' (elicitation, MS, BP34-5-s, 6)

In (61a), there is no overt DP projected as the internal argument of the verb saa 'cook'; and, in (61b), the argument of the postposition $-k u b a$ is projected as the pronominal element $p \dot{t}$.

There are two main mechanisms for creating gaps: $\mathrm{A}^{\prime}$-movement, like that found in English whquestions or relative clauses (Chomsky 1977:87), and abstraction over a resumptive pronoun. It is this latter kind of dependency that gives rise to the individual interpretation. The nominalization in (61a) has the following structure:

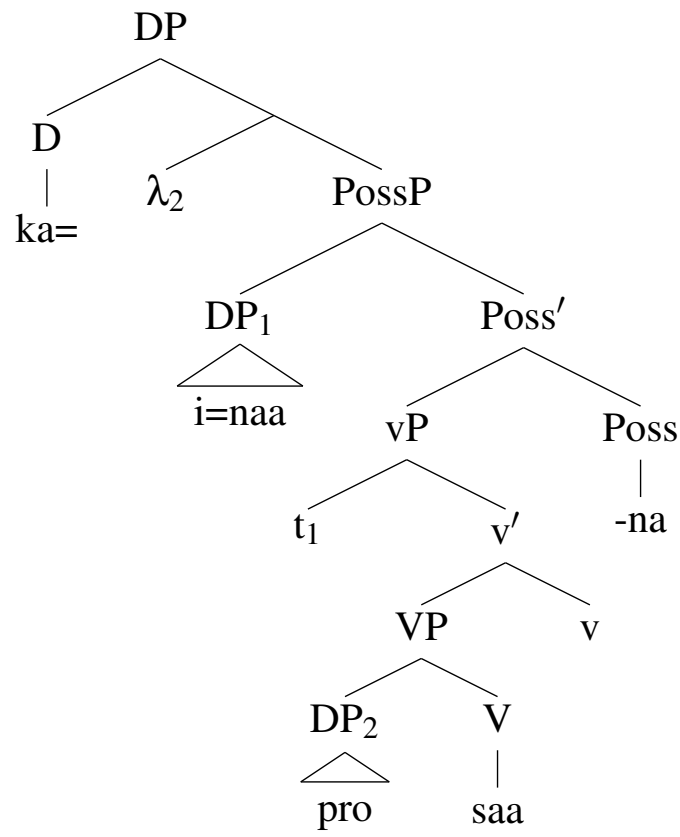

There is a null resumptive pronoun in direct object position. In (61b), the resumptive pronoun in oblique position is realized overtly as $p \dot{t}$. To derive the individual-type interpretation for nominalizations with $-n a$, I assume that a $\lambda$-operator can adjoin to the complement of $\mathrm{D}$, binding a resumptive pronoun in its scope.

The composition of this individual-denoting nominalization starts off much like the eventdenoting nominalization in $§ 3.2$. But one of the predicate's individual-type arguments is saturated 
by the free variable introduced by the resumptive pronoun, as shown in the following parsetree for (61a):

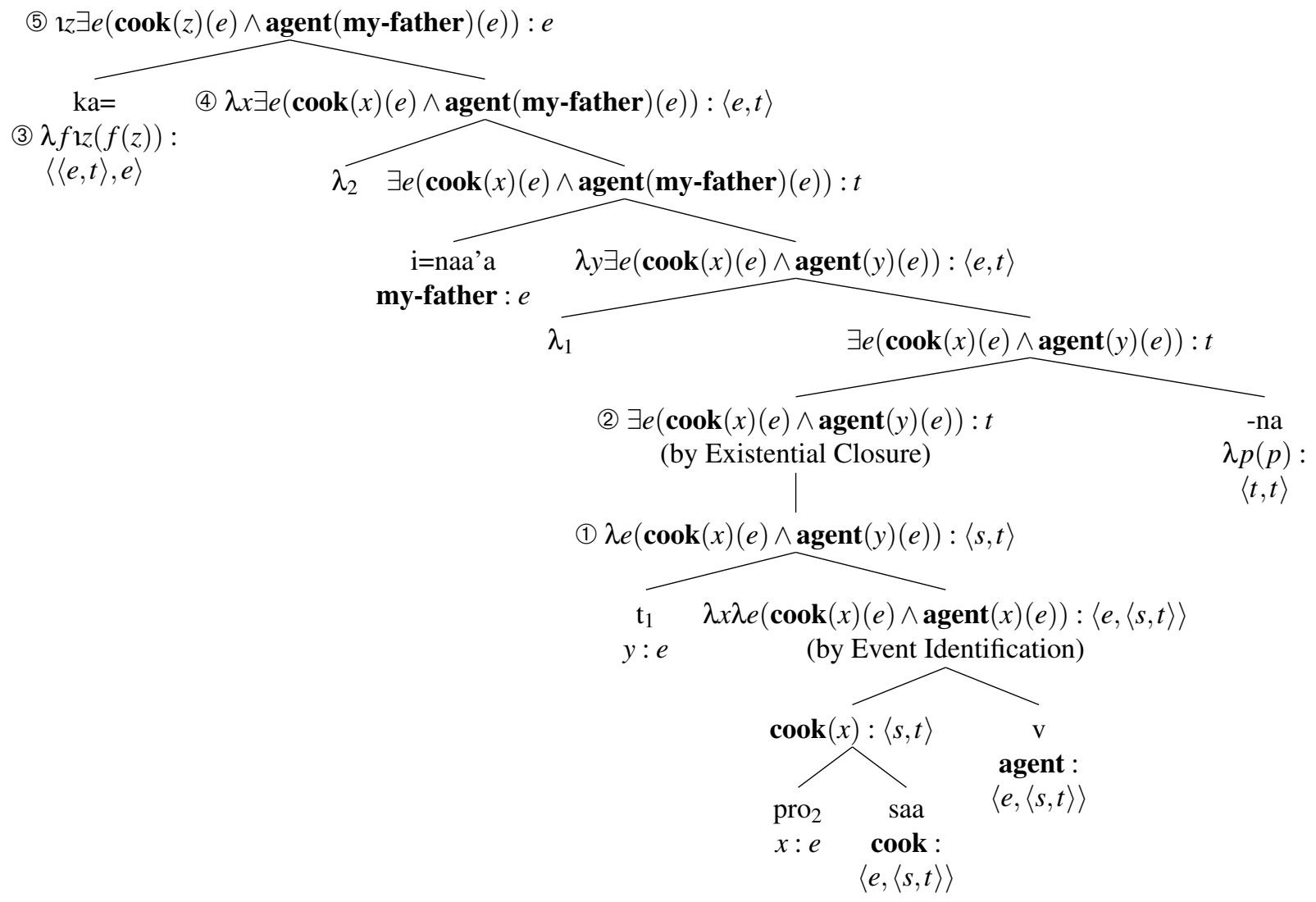

Once the predicate's individual-type arguments are saturated, the vP denotes a predicate of events (1). In this nominalization, however, the event argument is existentially bound by Existential Closure (2). This does not trigger a type mismatch since there is a resumptive pronoun inside vP. The set of entities required by the determiner as its argument (3) is created by the $\lambda$-operator abstracting over the resumptive pronoun (4). In the end, the DP refers to the individual that is cooked by the speaker's father (5)).

The motivation for inserting a $\lambda$-operator is semantic. The determiner requires a set of entities as its argument. ${ }^{17}$ Its complement can provide this only if a $\lambda$-operator abstracts over a free variable

\footnotetext{
${ }^{17}$ Note that the determiner can be an overt demonstrative or definite determiner, as in (61a), or it can be phonologically null. When the determiner is null, it picks out the unique (nonatomic) individual, much like a free relative (Jacobson 1995, Caponigro 2003). This can give rise to a universal-like interpretation:
}

(i) 'Having got there, we picked a lot [of chokecherries] at that place. Everyone, we picked along with our mother. Later on we, having picked a lot, we came back again.'

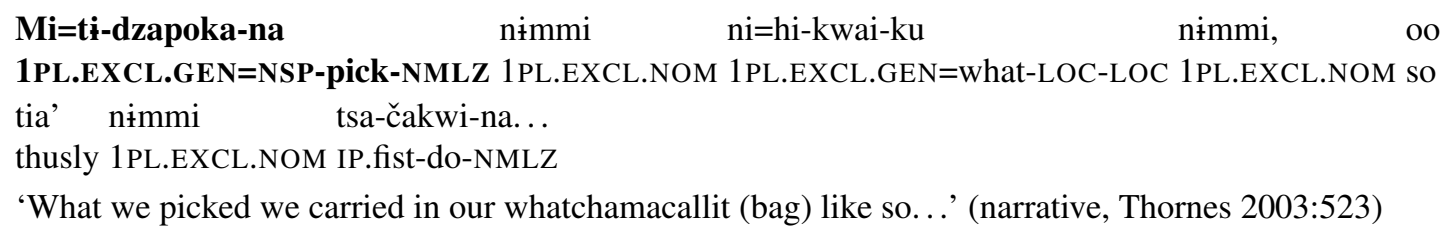

In (i), the speaker is talking about ALL of the chokecherries that were picked, not just a (unique) individual chokecherry. 
contained within it to create a set of entities. ${ }^{18}$

\subsection{Resumptive pronouns in Northern Paiute}

One might wonder whether the gap inside these nominalizations is really created by a resumptive pronoun, and not simply $\mathrm{A}^{\prime}$-movement. It is, after all, phonologically null in direct object position.

That is what we expect, however, if the gap is created by a resumptive pronoun. Crosslinguistically, resumptive pronouns are formally identical to pronouns. McCloskey (2006:96) states that he 'know[s] of no report of a language that uses a morphologically or lexically distinct series of pronouns in the resumptive function. ${ }^{19}$ In Northern Paiute, an argument can be realized as a null

\footnotetext{
${ }^{18}$ I argue elsewhere (Toosarvandani 2011) that the $\lambda$-operator can bind a free variable introduced by an expression other than a resumptive pronoun. The nominalization with -na in (i) describes an individual - the rabbit cooked by the speaker's mother-even though there is no obvious gap in the patient argument. The direct object of the verb saa 'cook' is the bare noun kammi 'rabbit'.
}

(i) Kai nï ka=i=bia kammi saa-na tika-kwi.

NEG 1SG.NOM DEF.ACC=1SG.GEN=mother rabbit cook-NMLZ eat-PROSP

'I won't eat the rabbit my mother cooked.' (elicitation, EM, BP32-4-s, 78)

This nominalization can be treated in a parallel fashion to ones containing a resumptive pronoun (61a-b). The bare noun is an indefinite, which under Heim's (1982) theory is interpreted as a restricted free variable that can be abstracted over. After combining with the definite determiner, the entire nominalization has the correct individual-denoting meaning:

$$
\llbracket(\mathrm{i}) \rrbracket=\mathfrak{L}(\operatorname{rabbit}(x) \wedge \exists e(\operatorname{cook}(x)(e) \wedge \operatorname{agent}(\mathbf{m y}-\mathbf{m o t h e r})(e))): e
$$

This is the same basic treatment that Basilico (1996) gives to deverbal nominalizations containing a Heimian indefinite in other languages (Lakhota, Mojave, Mooré, and Northern Athabaskan), though there they are traditionally called internally headed relative clauses.

${ }^{19}$ The resumptive pronoun $p \dot{i}$ that appears in oblique position might be unusual in this respect. It is potentially unique to nominalizations with -na, since it does not appear as the argument of a postposition elsewhere in the language. There might be some relationship between $p \dot{t}$ - and the so-called emphatic pronoun $p \dot{t} \dot{t}$. Since independent words in Northern Paiute must be bimoraic in length, it would not be implausible for $p \dot{\boldsymbol{t}}$ - to lengthen to $p \dot{\boldsymbol{t}} \boldsymbol{t}$ when standing on its own.

A semantic connection between the two forms is somewhat more difficult to identify. The emphatic pronoun, as its name suggests, lends emphasis to a DP, either by itself (i) or when it is supported by the enclitic $=s u$ (ii) or by $=s i m i$ 'alone, only' (iii).

$$
\text { Oka pii yaa su=toogga-tsi puni-kati. }
$$

3SG.ACC PRO there DEF.NOM=dog-DIM see-STAT

'Now that's what the dog was looking at, sitting there.' (prompted narrative, EM, BP25-2-t1, 7)

(ii) $\mathrm{Su}=$ naatsi'i $\mathbf{p} \mathbf{i} \mathbf{i}=\mathbf{s u}$ tika.

DEF.NOM=boy $\mathrm{PRO}=\mathrm{EMPH}$ eat

'The boy himself is eating.' (elicitation, EM, BP37-2-s, 16)

(iii)

$$
\begin{aligned}
& \mathrm{Su}=\text { nana } \quad \text { piì=simi } \text { oo siggwi kati. } \\
& \text { DEF.NOM=man } \\
& \mathrm{PRO}=\text { =alone there just sit.DUR }
\end{aligned}
$$

'The man is just sitting there by himself.' (elicitation, MS, BP33-3-s, 18)

In (i), for instance, pii emphasizes the third-person singular object of the verb, as reflected in the English translation, which is a reverse pseudocleft. In (ii-iii), the emphasis is realized in the English translations in the emphatic use of reflexive anaphors - i.e. the boy himself and the man... by himself. Further investigation is clearly needed to determine whether or not the emphatic pronoun can be identified with the resumptive pronoun. 
pronoun if it is given in the previous discourse, in direct object position (64a) as well as in subject position (64b).
a.
Pa'mogo $_{1}=$ bino'o $^{\prime}$
frog=PTC
$\mathrm{ka}=\mathrm{hanno}=\mathrm{sabbi}$
mia-hu. Kai nii
pro 1 punni.
DEF.ACC $=$ where=PTC go-PUNC NEG 1 SG.NOM
see.DUR

'And the frog ${ }_{1}$, I don't know where it went. I don't see it 1 .' (prompted narrative, MS, BP24-1-t3, 58-59)

b. Obina-ggwe yaisi $\mathbf{m i}=$ nigga-di ${ }_{1}=$ bino'o ka=paaskiti pibo'a. Yaisi

after-LOC PTC $\mathbf{P L}=$ dance-NMLZ=PTC DEF. ACC=basket throw.DUR PTC

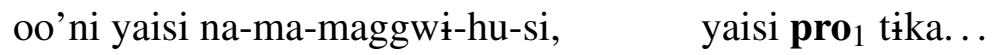

later PTC PASS-PLUR-finish-PUNC-SEQ PTC eat

'Afterwards the dancers 1 throw the basket. Then, after it is finished, they ${ }_{1}$ eat...' (narrative, MS, BP13-4-t2, 12-13)

Looking more deeply, there are several other properties of resumptive pronouns that we can use to distinguish them from the gap created by $\mathrm{A}^{\prime}$-movement: i) absence of weak crossover effects, ii) insensitivity to constraints on movement, and iii) failure to license parasitic gaps. ${ }^{20}$ In what follows, I show that the resumptive pronouns inside individual-denoting nominalizations with -na do not exhibit weak crossover (\$3.4.1) and that they do not obey the standard constraints on extraction, insofar as they can be tested in Northern Paiute (\$3.4.2). The third property above — the failure of resumptive pronouns to license parasitic gaps - is of little use because Northern Paiute has null arguments. So, I provide an additional argument that individual-denoting nominalizations with -na contain resumptive pronouns based on their antilocality property (§3.4.3).

\subsubsection{Weak crossover effects}

While resumptive pronouns show strong crossover effects, just like the traces of $\mathrm{A}^{\prime}$-movement, they do not exhibit weak crossover effects (Sells 1984:69-84, McCloskey 1990:236f.). In Northern Paiute, wh-movement does exhibit weak crossover, as shown in (65).
a. Haga $_{1} \mathrm{t} \dot{\mathrm{i}}={ }_{1}$ ddua tikka-ggí-ti?
who REFL=child eat-APPL-TNS
'Who fed their $_{1}$ child?' (elicitation, EM, BP37-3-s, 13)
b. * Haga 1 ti= ${ }_{1}$ bbia tika-ggi-ti?
who REFL=mother eat-APPL-TNS
Intended: 'Who 1 was fed by their 1 mother?' (elicitation, EM, BP37-3, 32:28)
c. * Haga ${ }_{1} \mathrm{u}={ }_{1}$ bbia tika-ggi-ti?
who 3SG.GEN=mother eat-APPL-TNS
Intended: 'Who 1 was fed by their 1 mother?' (elicitation, EM, BP43-2, 30:10)

\footnotetext{
${ }^{20}$ There are languages, such as Swedish (Engdahl 1985) and Vata (Koopman 1992), that have resumptive pronouns which do behave, for all intents and purposes, like the gap created by $\mathrm{A}^{\prime}$-movement. These might be analyzed as the overt realization of an $\mathrm{A}^{\prime}$-trace. Other languages, such as English, only allow an 'intrusive' resumptive pronoun when extraction is not possible (Chao and Sells 1983, Sells 1984). I will not be concerned with these types of resumptive pronouns.
} 
In (65a), the genitive reflexive anaphor $t \dot{t}=$ can be bound by a subject wh-phrase when it occurs inside the object. But when the anaphor appears inside the subject, as in (65b), it cannot be bound by an object wh-phrase that has $\mathrm{A}^{\prime}$-moved past it. The ungrammaticality of $(65 \mathrm{~b})$ cannot be attributed solely to a violation of Principle A, since the nonreflexive possessive pronoun in (65c) is also ungrammatical in the same crossover configuration.

In contrast, when the genitive reflexive anaphor occurs as the possessor in a nominalization, it can be bound by the operator that binds the (null) resumptive pronoun inside the embedded vP:

$$
\text { Tíbbia mutuhe-na yaka. }
$$

REFL=mother kiss-NMLZ cry.DUR

'The one ${ }_{1}$ kissed by their 1 mother is crying.' (elicitation, EM, BP37-3-s, 15)

The nominalization in (66) describes the individual who was kissed by the individual's mother. Its structure is shown below.

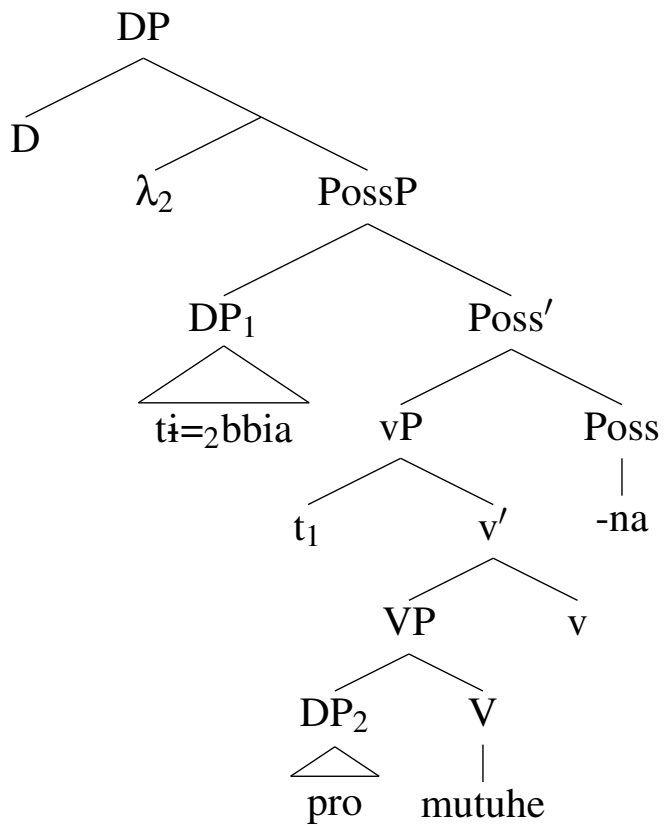

This is a weak crossover configuration since the $\lambda$-operator that binds the resumptive pronoun inside the vP also has the genitive reflexive anaphor $t \dot{t}=$ in its scope. Such a configuration is ruled out for operators that undergo $\mathrm{A}^{\prime}$-movement, but it is grammatical for the operators that bind resumptive pronouns.

\subsubsection{Constraints on movement}

Resumptive pronouns also come apart from $\mathrm{A}^{\prime}$-movement in not obeying the standard restrictions on extraction, such as island constraints. Unfortunately, Northern Paiute does not allow us to test many of these restrictions, because it does not have the necessary embedding structures. ${ }^{21}$

\footnotetext{
${ }^{21}$ For instance, it does not obey the Left Branch Condition (see §2.3.3), and it lacks the syntactic structures needed to construct the other islands. There are no coordinate structures to test the Coordinate Structure Constraint, and there are no tensed embedded clauses, as far as I know, that can be used to test the Sentential Subject Constraint.
} 
There is, however, one constraint on $\mathrm{A}^{\prime}$-movement that is available. Wh-phrases cannot be extracted from within a PP — that is, postpositions must be pied-piped, as - kuba is in (68a). Stranding the postposition, either by itself (68b) or with the pronominal element $p \dot{t}$ as its host (68c), is ungrammatical.

$$
\begin{aligned}
& \text { a. Hi-kuba } a_{1} \dot{\mathrm{q}} \quad \mathrm{ka}=\text { wihi } \quad \mathrm{t}_{1} \text { tiki? } \\
& \text { what-LOC } 2 \text { SG.NOM DEF.ACC }=\text { knife put.DUR } \\
& \text { 'What did you put the knife on?' (elicitation, MS, BP11-5-s, 20) } \\
& \text { b. * } \mathbf{H i}_{1} \text { it ka=wihi } \mathrm{t}_{1} \text {-kuba tigi-hu? } \\
& \text { what } 2 \text { SG.NOM DEF.ACC=knife -LOC put-PUNC } \\
& \text { Intended: 'What did you put the knife on?' (elicitation, EM, BP37-3, 19:57) } \\
& \text { c. * Hi } \text { i }_{1} \text { i⿱ } \quad \text { ka=wihi pi- }{ }_{1} \text { kuba tigi-hu? } \\
& \text { what 2SG.NOM DEF.ACC=knife PRO-LOC put-PUNC } \\
& \text { Intended: 'What did you put the knife on?' (elicitation, EM, BP37-3, 20:45) }
\end{aligned}
$$

In nominalizations with -na, however, a preposition can of course be stranded. That is how they are able to describe an individual that is projected as an oblique argument. Consider, again, the sentence in (69), repeated from (61b) above.

$$
\begin{aligned}
& \text { Ka=i=naa'a pi-kuba kati-na nï } 1 \text { timi-dua. } \\
& \text { DEF.ACC=1 SG.GEN=father PRO-LOC sit-NMLZ 1SG.NOM buy-IRR } \\
& \text { 'I will buy the one my father is sitting on.' (elicitation, MS, BP34-5-s, 6) }
\end{aligned}
$$

The nominalization describes the argument of a locatival postposition, which is stranded inside the vP. Since a postposition must be pied-piped when its argument has been extracted, the gap in this nominalization must be produced by a resumptive pronoun.

\subsubsection{The Highest Subject Restriction}

Resumptive pronouns exhibit what McCloskey (1990:210) calls the HIGHEST SUBJECT RESTRICTION. They cannot occupy a subject position immediately subjacent to their binder. The proper analysis of this phenomenon remains controversial, though often it is related to the more general antilocality property of (nonreflexive) pronouns embodied in Principle B (Borer 1984, McCloskey 1990; see McCloskey 2006 for additional discussion and references). I will not attempt to provide a theory of why resumptive pronouns should obey this constraint. I will simply use it to argue that the gap in individual nominalization with - $n a$ is created by a resumptive pronoun.

It might be possible to test the Complex NP Constraint using nominalizations themselves. The necessary configuration would be the following:

(i) $\quad\left[\right.$ DP $\lambda_{1}\left[\operatorname{PossP}_{\text {DP }}\left[{ }_{\mathrm{vP}}\left[\mathrm{DP}\left[\mathrm{PossP}_{\mathrm{DP}}\left[\mathrm{vPP}_{1} \mathrm{~V}\right]-\right.\right.\right.\right.$-na $\left.\left.]\right] \mathrm{V}\right]$-na $\left.]\right]$

But such complex nominalizations are impossible to elicit. This might be because placing one nominalization inside another results in center embedding. Two possessor DPs would be followed by the resumptive pronoun followed by two verbs bearing -na. As Chomsky (1961) observes for English, multiple central embedding are unacceptable for independent reasons: e.g. The rat the cat the dog chased killed ate the malt. 
First we need to figure out how the Highest Subject Restriction applies in the nominal domain. The DP that corresponds to the subject of a clause sits in Spec-PossP. The Highest Subject Restriction states, then, that a resumptive pronoun is not able to occupy this position when the resumptive pronoun's binder is located within the same subjacency domain. In other words, the following configuration is ruled out by the Highest Subject Restriction:

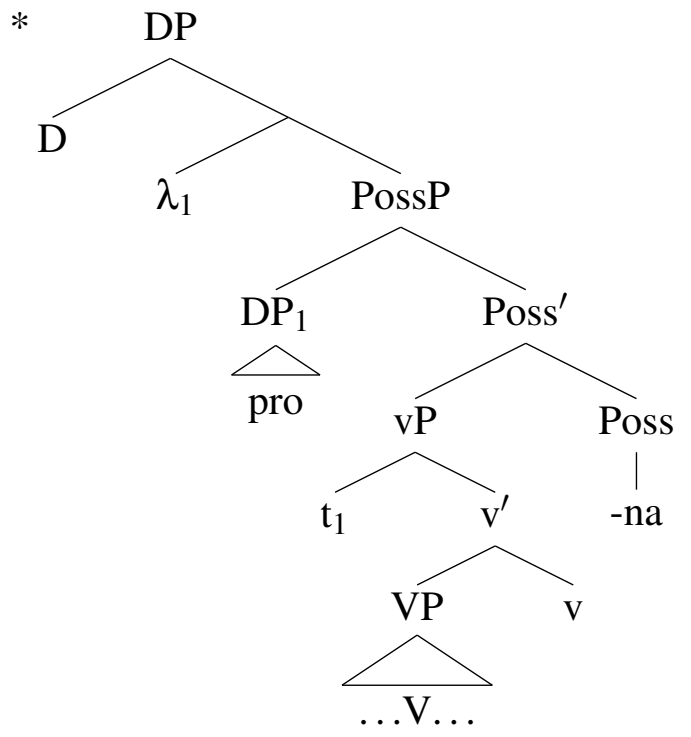

A nominalization with the structure in (70) would describe the highest argument of the embedded verb. However, such nominalizations with a gap in the position of the POSSESSOR are never attested in Northern Paiute:
a. * Nii $\quad \mathbf{k a}=\mathbf{t} \mathbf{i}=\mathbf{n a a} \mathbf{a}$
tona-hu-na
mutuhe-hu.
1SG.NOM DEF.ACC=REFL=father punch-PUNC-NMLZ kiss-PUNC
Intended: 'I kissed the one who punched my father.' (elicitation, EM, BP37-3, 57:45)
b. * Su=paayai-na habi-hu.
DEF.NOM=get.drunk-NMLZ fall-PUNC
Intended: 'The drunk one fell down.' (elicitation, EM, BP39-2, 1:00:39)

That is, when nominalizations with - $n a$ describe an individual, this must be an argument of the embedded verb that is not the highest argument.

\section{The interpretation of nominalizations with $-d i$}

Nominalizations that describe the highest argument of the verb are created with the $-d \dot{t}$ nominalizer, regardless of the thematic role of this argument:
a. $\quad \mathbf{S u}=\mathbf{k u t s u}$
patsa-di mia-hu.
DEF.NOM=cow kill.SG-NMLZ go-PUNC

'The cow killer left.' (elicitation, EM, BP37-1-s, 16) 
b. Su=na-gwitama-di wadzi-mia-hu.

DEF.NOM=PASS-lock.up-NMLZ hide-go-PUNC

'The one who should be locked up ran away.' (elicitation, MS, BP34-4-s, 24)

c. Ka=idziggwi ka=kwopika-winni-di nił ki’a.

DEF.ACC=blanket DEF.ACC=shiver-STAT-NMLZ 1 SG.NOM give.DUR

'I gave the blanket to the one who is shivering.' (elicitation, MS, BP34-3-s, 28)

d. $\mathrm{Su}=$ nana katsiponoa-di-ma kati-hu.

DEF.NOM=man DEF.ACC=be.round-NMLZ-LOC sit-PUNC

'The man sat on the round thing.' (elicitation, EM, BP34-3-s, 34)

The nominalization in (72a) describes the agent of the transitive verb patsa 'kill (sg.)'; the one in (72b) the patient of the passive verb nagwitama 'be locked up'; the one in (72c) the patient of the unaccusative verb kwopika 'shiver'; and, the one in (72d) the sole argument of the stative verb patsiponoa 'be round'.

The nominalizations in $(72 \mathrm{a}-\mathrm{d})$ all have the following schematic structure, where $-d \dot{t}$ is the realization of a Poss head that takes a vP complement:

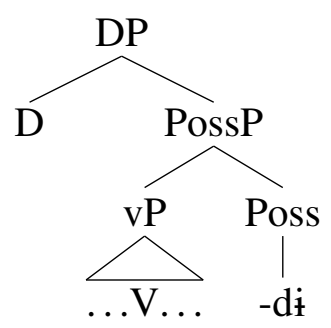

Since there is no $\mathrm{T}$ inside these nominalizations and $-d \dot{t}$ does not project a specifier, there is one case too few. In particular, as I discuss in $\$ 4.1$, there is no case (nominative or genitive) to license an overt DP in the highest argument position of the embedded verb. Consequently, as I show in $\S 4.2$, this position is occupied by a phonologically null argument (PRO) that does not need case. It is bound by a $\lambda$-operator to give rise to the individual interpretation. ${ }^{22}$ The event interpretation of nominalizations with $-d \dot{t}$ is restricted to zero-place predicates. This follows from the current account, as I show in $\$ 4.3$, because the verb's event argument can only be left unsaturated when it takes no individual-type arguments.

\subsection{The individual interpretation}

The individual nominalization with $-d i$ in $(72 a)$ has the following structure:

\footnotetext{
${ }^{22}$ Krause (2001) makes a similar proposal for reduced relative clauses, where the highest argument of a verb raises to be the head of a reduced relative clause because it cannot get nominative case.
} 
(74)

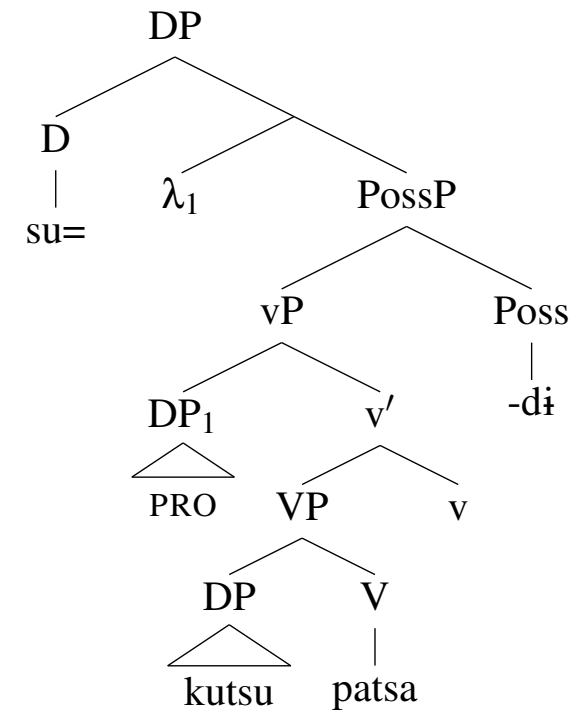

The direct object kutsu 'cow' gets accusative case from v. A DP in Spec-vP, however, would be unable to get case. There is no $\mathrm{T}$ inside the nominalization, and since $-d \dot{t}$ does not project a specifier into which the DP can raise and get genitive case, there simply is no case to assign it. Consequently, this argument of the verb in (74) is projected as a phonologically empty argument that does not need case (PRO; Chomsky 1981).

This nominalization with $-d \dot{t}$ describes an individual because PRO is abstracted over by the same $\lambda$-operator found in nominalizations with $-n a$. The semantic composition of (72a) is shown below.

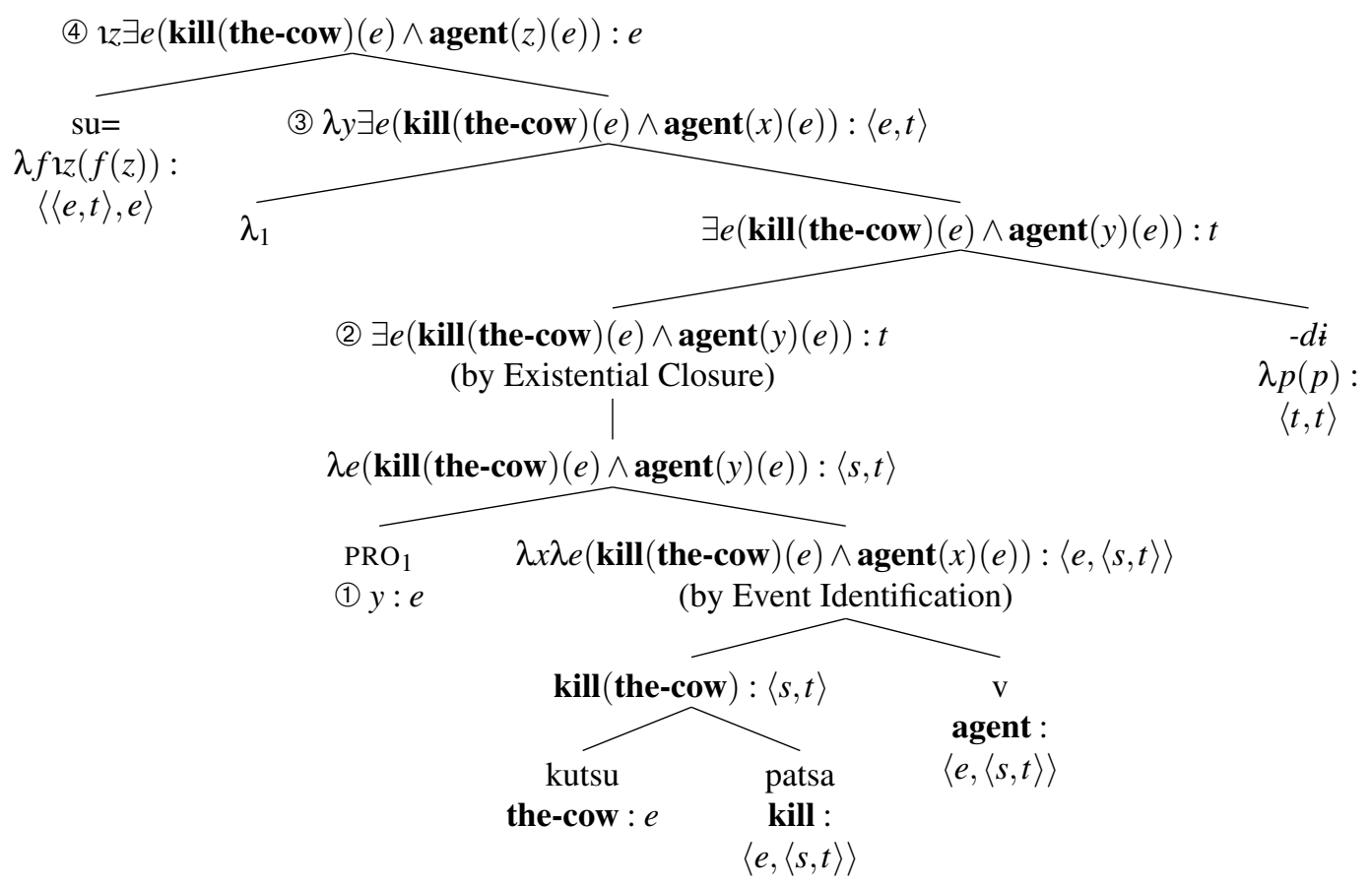

The null argument contributes an individual-type variable (1), which saturates the verb's external argument. The event argument is existentially bound by Existential Closure at the vP level (2). (Again, I assume that the nominalizer $-d \dot{t}$ denotes the identity function, since it does not contribute 
to the meaning of the nominalization.) Then, the variable contributed by PRO is abstracted over by a $\lambda$-operator that adjoins to the sister of $\mathrm{D}$ (3). The resulting set of individuals serves as the argument for the determiner, so that the entire DP refers to the individual who is the agent of the event of killing the cow (4)).

The interpretations of the nominalizations in $(72 \mathrm{~b}-\mathrm{d})$, where $-d \dot{t}$ applies to an unaccusative, passive, or stative verb, arise in a similar fashion. These nominalizations are also missing one case, since by Burzio's Generalization v cannot assign accusative case if it does not assign an external argument theta role. In a ordinary clause, the internal or stative arguments of these verbs would raise to subject position. But in a nominalization with $-d \dot{t}$, they are realized as PRO, so that the nominalization describes the internal or stative argument.

\subsection{Evidence for PRO}

We might consider an alternative to PRO. Say that, when the highest argument of the verb is not able to get case, it is simply not projected at all. This would leave that argument of the predicate unsaturated, yielding the same interpretation as $\lambda$-abstraction over PRO. There is evidence from the binding of reflexive and nonreflexive pronouns, however, that the highest argument in a nominalization with $-d \dot{t}$ is in fact syntactically projected. ${ }^{23}$

In Northern Paiute, the genitive reflexive anaphor $t \dot{t}=$ obeys a constraint like Principle A: it must be bound, as shown in (76a). In contrast, the (nonreflexive) genitive proclitic pronoun $u=$ obeys something like Principle B: it must be free in its binding domain, as shown in (76b).
a. $\quad \mathbf{S u}=$ nana $\mathbf{a}_{1} \quad \mathrm{ka}=\mathbf{t} \mathbf{i}={ }_{1}$ ggutsu kwati-hu.
DEF.NOM=man DEF. $A C C=$ REFL $=$ cow shoot-PUNC
'The man $_{1}$ shot his 1 cow.' (elicitation, EM, BP37-3-s, 32)
b. * $\mathbf{S u}=\mathbf{n a n a} \mathbf{a}_{1} \quad \mathbf{u}={ }_{1}$ ggutsu kwati-hu.
DEF.NOM=nana 3SG.GEN=cow shoot-PUNC
Intended: 'The $\operatorname{man}_{1}$ shot his 1 cow.' (elicitation, EM, BP37-3, 1:20:20)

\footnotetext{
${ }^{23}$ Baker and Vinokurova (2009:548) use the same argument to support the presence of PRO in so-called agent nominalizations in Gĩkũyũ (Niger-Congo, Bantu: Kenya). Like the $-d \dot{t}$ nominalizer in Northern Paiute, the $-i$ suffix turns a verb into a nominal that describes the verb's highest argument, e.g. the agent (i). (The numbers in the interlinears for the Gĩkũyũ examples represent noun class, not person.)

(i)
A-thĩnj-í
mbũri ̃ú̃u acio ní-má-á-tūm-a
tũ-caamb-e.

2-slaughter-NMLZ 10goats badly 2DEM FOC-2.SBJ-PRF-make-IND 2.SG.SBJ-bad.reputation-SBJV

'Those (people) who slaughter goats badly have given us a bad reputation.' (Mugane 2003:237)

They argue (p. 547f.) that these nominalizations do not contain nominative case, so that the highest argument of the verb is realized as PRO. It is able to license a reflexive pronoun (realized as an $i$ - prefix on the verb) in the two nominalizations in (ii).

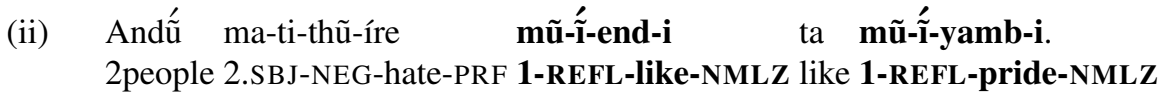

'People don't hate one who likes him/herself as much as one who is full of him/herself.' (Mugane 2003:239)

Baker and Vinokurova write (p. 548) that they 'suspect that this sort of nominalization [in Gĩkũyũ] is relatively rare.' But if it has the same syntax and semantics as nominalizations with - $d \dot{t}$ in Northern Paiute, perhaps it is not so rare after all.
} 
The genitive reflexive anaphor and nonreflexive proclitic pronoun have the same referential possibilities in nominalizations with $-d i$ :
a. $\mathrm{Nii} \quad \mathrm{ka}=\mathbf{t} \mathbf{i}=$ bbia
mutuhe-di pisapi.
1SG.NOM DEF.NOM=REFL=mother kiss-NMLZ like.DUR
'I like the one ${ }_{1}$ who is kissing his ${ }_{1}$ mother.' (elicitation, EM, BP37-3-s, 36)
b. * Nii u=bbia mutuhe-di pisapi.
1SG.NOM 3SG.GEN=mother kiss-NMLZ like.DUR
Intended: 'I like the one ${ }_{1}$ who is kissing his ${ }_{1}$ mother.' (elicitation, EM, BP37-3, $1: 37: 20)$

This should only be possible if there is another DP inside these nominalizations to bind them. The sentence in (77a) is grammatical since $t \dot{t}=$ is bound by a PRO in Spec-vP. Similarly, the sentence in (77b) is ungrammatical under the intended interpretation since $u=$ is not free. It is c-commanded by, and coreferential with, PRO in Spec-vP.

We should be careful here to distinguish syntactic binding from semantic binding. Under standard assumptions, the distribution of reflexive and nonreflexive pronouns is mediated by SYNTACTIC binding, which Binding Theory defines as a relation between DPs (based on c-command and coreference). In contrast, semantic binding is a relation between a $\lambda$-operator (or other operator) and a variable. Both reflexive and nonreflexive pronouns can be semantically bound, but only a reflexive pronoun must be syntactically bound. Consequently, even though PRO is semantically bound by a $\lambda$-operator in nominalizations with $-d \dot{t}$, we can use syntactic binding and the distribution of reflexive and nonreflexive pronouns to provide evidence for its presence. ${ }^{24}$

\subsection{The event interpretation}

When the verb embedded by $-d \dot{t}$ takes one or more individual-type arguments, the highest one cannot get case and must be realized as PRO. By abstracting over the variable it contributes, the nominalization describes an individual, and the verb's event argument is existentially bound. Say, though, that every individual-type argument were to get case. A nominalization with - $d \dot{t}$ would then describe the verb's event argument, which would be its highest (and only) argument.

This happens in exactly one circumstance - when the embedded predicate takes No individual arguments. The nominalizations of the weather verbs tïggwa 'snow' and pauma 'rain' describe an event: 25

\footnotetext{
${ }^{24} \mathrm{~A}$ reviewer points out that there have been some attempts to collapse syntactic binding into semantic binding (Reinhart 1983a,b, Heim 1998). If these are successful, we might think that the data in (77) would not show anything about the presence of a PRO in nominalizations with - $d \dot{t}$. A reflexive pronoun could, for instance, always be licensed by a $\lambda$-operator adjoined to the sister of $\mathrm{D}$. While this would account for the presence of a reflexive pronoun inside a nominalization with $-d \dot{t}$, it would not derive the correct interpretation for (77a). If the external argument of the verb were not projected syntactically, it would remain unsaturated and not be available for (semantic) binding. Consequently, a $\lambda$-operator would only be able to bind the reflexive pronoun. This would not give rise to the interpretation in (77a) in which the external and internal arguments corefer.

${ }^{25}$ Observe that (78a) forms a near minimal pair with the event nominalization of a weather verb by $-n a$ in (47). Under my proposal, they should have the same truth conditions. I do not know, however, whether there are any differencessemantic or pragmatic — between the two types of deverbal nominalization.

I will point out that English also has multiple ways of describing the same event. A perception verb can take as its
} 

a. Niq ka=tiiggwa-di punni.
1SG.NOM DEF.ACC $=$ snow-NMLZ see.DUR

'I see it snowing.' (elicitation, EM, BP37-2-s, 32)

b. Pauma-di tïinaha-hu.
rain-NMLZ stop-PUNC

'The rain stopped.' (elicitation, EM, BP33-2-s, 27)

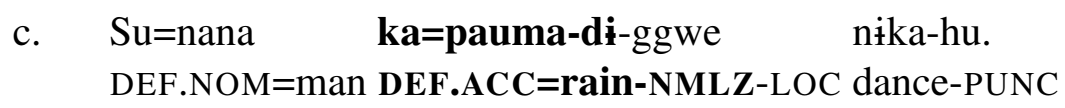

'The man was dancing when it was raining.' (elicitation, EM, BP32-4-s, 25)

The nominalization in (78a) refers to an event of snowing that is perceived by the speaker, and the one in (78b) to an event of raining that ends. The nominalization in (78c) is the argument of the postposition -ggwe, which has a temporal sense that locates the raining event described by the nominalization at the same time as the dancing event.

The semantic composition of the event nominalizations in $(78 \mathrm{a}-\mathrm{c})$ is nearly identical to the composition of individual-denoting nominalizations. This is illustrated for (78a):

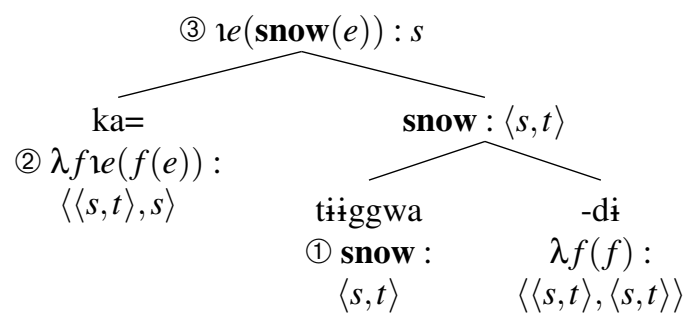

The verb denotes a set of events (1). In a clause the event argument would be existentially bound, but since the definite determiner $k a=$ requires a set of entities as its argument (2), the Existential Closure operation does not apply. The entire DP thus refers to the event of its snowing (3).

The nominalizer $-d \dot{t}$ only has an event interpretation when it applies to a very small class of predicates. Unlike - na, it does not project a specifier and does not make an additional genitive case available. This consequently produces an individual interpretation only when the highest argument of the verb is realized without case as a null argument that is abstracted over (PRO). And, it produces an event interpretation only when the verb takes no individual-type arguments.

\section{How English is (not) like Northern Paiute}

While deverbal nominalizations in Northern Paiute can have either an event or an individual interpretation, why do parallel nominalization patterns in other languages not exhibit the same variabil-

internal argument a bare infinitival complement (i), a POSS-ing gerund (ii), or an ACC-ing gerund (iii).

(i) I saw him eat the cake.

(ii) I saw his eating the cake.

(iii) I saw him eating the cake.

There is probably some sort of difference amongst these three constructions, even though superficially they appear to have the same truth conditions. I leave this question for future investigation. 
ity? Consider the two English nominalization patterns from the introduction: the POSS-ing gerund, illustrated in (80a), and agent nominalizations with -er, illustrated in (80b).
a. I witnessed Caesar's burning the city.
b. The seller of counterfeit stock was jailed.

The POSS-ing gerund can only describe an event - never an individual - while the agent nominalization can only describe an individual. Below I explore why English is different from Northern Paiute in this respect.

The POSS-ing gerund, I argue in $§ 5.1$, has the same basic structure as a nominalization with -na. But it only describes events because English lacks the system of operators and resumptive pronouns that give rise to the individual interpretation in Northern Paiute. In contrast, while the -er nominalizer in English might bear a passing similarity to - $d \dot{t}$ in Northern Paiute, I show in $\$ 5.2$ that its syntax and semantics are actually quite different. An event interpretation is never possible since the verb's event argument is closed off by the nominalizer suffix itself.

\subsection{The POSS-ing gerund}

Though there are many analyses of the POSS-ing gerund in English, most generative approaches take the -ing suffix to realize some kind of head in the extended nominal projection. ${ }^{26}$ Early accounts assumed that it was an $\mathrm{N}$ that takes a verb phrase complement (Horn 1975, Jackendoff 1977:222f.). This seems unlikely, though, since -ing does not have the right kind of meaning for a noun (it does not denote a set of entities like a common noun). Instead, we might think that -ing is a D. But Abney (1987:193-209) rejects this possibility because it is able to cooccur with the Saxon genitive 's, which is in complementary distribution with other determiners.

Baker (2005) proposes that the -ing suffix in POSS-ing gerunds realizes a nominal functional head somewhere between $\mathrm{N}$ and $\mathrm{D}$ that is the nominal equivalent of $\mathrm{T}$ (or Infl) (see the earlier work of Baker 1985 and Milsark 1988 as well). Since this is precisely the position and function of the Poss head, I propose that -ing realizes the Poss head when it takes a vP complement. Like -na in Northern Paiute, it projects a specifier where possessors are assigned case. Under this analysis, the POSS-ing gerund in (80a) has the following structure:

\footnotetext{
${ }^{26}$ There are alternatives. For instance, gerunds could not be endocentric (Schachter 1976, Pullum 1991), or they could have the features of both nouns and verbs (Malouf 2000a,b, Hudson 2003), or the -ing suffix (or some abstract correlate of it) could be adjoined to a verb phrase (Abney 1987:241-244, Yoon 1996). For reasons of space, I set these possibilities aside.
} 
$(81)$

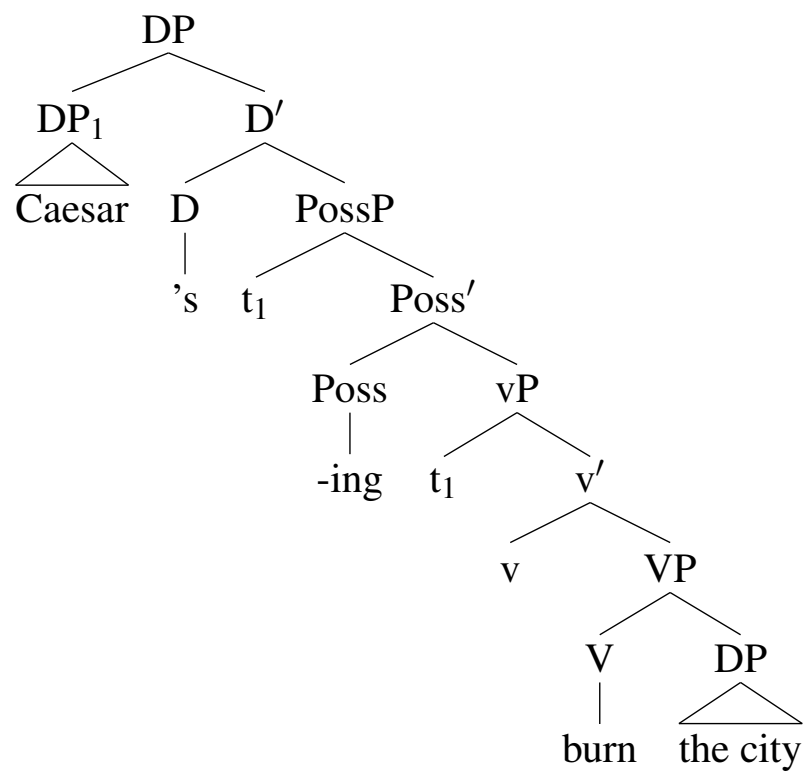

The external argument of the embedded verb raises to Spec-PossP, where it receives case, before raising to its surface position in Spec-DP, as Abney (1987:79) proposes. Just as we would expect if the POSS-ing gerund contains a vP, it assigns accusative case to the direct object, and it can include verbal modifiers such as manner adverbs (Caesar's quickly burning the city) (Abney 1987:182). Yet, the POSS-ing gerund does not assign nominative case to the highest argument of the base verb - what would be the subject in a clause - which is instead realized as a possessor.

If -ing is indeed the overt realization of the Poss head, POSS-ing gerunds should have the same properties that we saw nominalizations with $-n a$ do: i) they should be able to contain nominal categories located above Poss; ii) they should take an obligatory possessor; and, iii) they should have an event interpretation. Below, I show that POSS-ing gerunds have all three properties.

It is important to note that I am proposing the structure in (81) only for the POSS-ing gerund. It is not necessarily suitable for other deverbal nominalizations created by the -ing suffix, such as the ACC-ing gerund in (82) or derived nominals like (83).

(82) I witnessed Caesar burning the city.

(83) I witnessed Caesar's burning of the city.

There have been attempts to unify the ACC-ing gerund and derived nominals with the POSS-ing gerund. For example, Abney (1987:222-230) proposes that the same -ing suffix creates all three nominalization patterns. The two gerunds would embed a somewhat larger verbal constituent, while derived nominals would embed a smaller one, possibly just the verb (though see Alexiadou 2001 and Borer 2003). Except for some tentative suggestions in footnote 28 towards assigning the ACC-ing gerund the structure in (81), I set these other nominalization patterns aside to focus just on the POSS-ing gerund.

\subsubsection{Other nominal categories inside POSS-ing gerunds}

If -ing realizes the Poss head, POSS-ing gerunds should be able to contain functional categories located above Poss in the extended nominal projection. The two main candidates are Num and D, both of which can appear inside a possessive description: 
John's dogs scared me.

Num is realized as the plural $-s$ suffix on the head noun, and D as the Saxon genitive 's (Abney 1987:79).

It is not possible for the plural suffix — and hence Num — to appear inside a POSS-ing gerund:

* I witnessed Caesar's burnings the city.

But this restriction arises for independent reasons. Borer (2005:239-245) shows that other event nominalizations can only bear plural marking when the embedded predicate is telic:
a. the pilot's crossings of the Pacific
b. \# the team's swimming of laps

The predicate cross the Pacific has an inherent end point, while swim laps has no inherent end point. While derived nominals inherit the telicity of the embedded predicate, Alexiadou et al. (2010:552-556) argue that POSS-ing gerunds are always atelic. ${ }^{27}$ Consequently, they do not allow plural marking for independent reasons, and the ungrammaticality of (85) tells us nothing about the structure of the POSS-ing gerund.

Assuming that 's is a determiner, we have already seen that D can appear inside POSS-ing gerunds. But this is the only determiner that can appear inside possessive descriptions in English, and hence also in POSS-ing gerunds. This contrasts with Northern Paiute, which allows the definite determiners $s u=$ and $k a=$ inside both its possessive descriptions and its nominalizations with $-n a$ and $-d i($ see $\$ 2.2) .^{28}$

\subsubsection{An obligatory possessor inside POSS-ing gerunds}

If -ing realizes Poss when it projects a specifier, then POSS-ing gerunds should always contain a possessor. This is indeed the case, as Abney (1987:183) observes. The possessor in a POSS-ing gerund cannot be omitted (87), unlike the possessor in either a possessive description (88a) or a derived nominal (88b).

\footnotetext{
${ }^{27}$ I leave for future research where this aspectual contribution comes from. Alexiadou et al. observe (p. 554 fn. 15) that it does not come from the -ing suffix itself. This makes sense if it realizes the Poss head, which I am arguing is semantically contentless.

${ }^{28}$ There might be one other determiner besides 's that appears inside nominalizations with -ing. In the ACC-ing gerund in (i), 's is absent, and when the external argument is a pronoun, it bears accusative case.

(i) $\left\{\begin{array}{l}\text { John } \\ \text { Him }\end{array}\right\}$ building the bridge ruined the company.

The traditional story, as told by Abney (1987:222-231), is that the POSS-ing gerund embeds a smaller constituent, such as a vP, while the ACC-ing gerund embeds a full clause, a TP.

Portner (1992:88-145) shows convincingly, however, that ACC-ing and POSS-ing gerunds do not embed differentsized verbal constituents. He attributes their differences in structure and interpretation to a contrast in DEFINITENESS. While the POSS-ing is headed by the definite determiner 's, the ACC-ing gerund is headed by a null indefinite determiner. Translating Portner's insight into the current framework, we could say that both the POSS-ing and ACC-ing gerunds involve the same nominalizer, a Poss head realized as -ing. While it assigns genitive abstract case to the DP in its specifier, this is realized morphologically as (default) accusative case. In an ACC-ing gerund, the (indefinite) determiner is phonologically empty, so the subject looks like it has accusative case. In a POSs-ing gerund, the determiner is 's, which causes accusative pronouns to be pronounced as morphologically genitive pronouns, i.e. him's $\rightarrow$ his (Hudson 2003:603).
} 


$$
\begin{aligned}
& \text { I witnessed }\left\{\begin{array}{c}
\text { Caesar's } \\
* \text { the }
\end{array}\right\} \text { burning the city. } \\
& \text { a. I witnessed }\left\{\begin{array}{l}
\text { John's } \\
\text { the }
\end{array}\right\} \text { will. } \\
& \text { b. I witnessed }\left\{\begin{array}{l}
\text { John's } \\
\text { the }
\end{array}\right\} \text { construction of the house. }
\end{aligned}
$$

It is tempting to attribute the ungrammaticality of the POSS-ing gerund without a possessor in (87) entirely to the failure of the embedded verb's external argument to project (a violation of the Theta Criterion). Baker (1985:7) observes, however, that predicates with no unsaturated arguments such as a weather verb (89a) or a predicate like be certain that does not assign a theta role to its subject $(89 b)$ - can occur in a POSS-ing gerund.
a. I am disappointed by $\left\{\begin{array}{c}\text { its } \\ * \text { the }\end{array}\right\}$ raining all day.
b. I am disappointed by $\left\{\begin{array}{c}\text { its } \\ * \text { the }\end{array}\right\}$ being certain that she'll quit.

(Baker 1985:7)

There is some dispute about whether these examples are grammatical (Abney 1986:16, Abney 1987:208). But there are plenty of naturally occurring examples of both types:

a. The idea is said to have originated in its raining on the day on which it was intended to remove his remains... ${ }^{29}$

b. Moreover, and this is part of Strawson's Point, indignation differs from its seeming that a sanction would be desirable. . ${ }^{30}$

The predicates embedded in these POSS-ing gerunds in (89-90) take no arguments that need case. Nonetheless, they must have a possessor, even if it is nothing more than the expletive pronoun its.

\subsubsection{An event interpretation for POSs-ing gerunds}

If -ing realizes the Poss head in POSS-ing gerunds, then they should be able to describe an event. This is the interpretation that we saw in $\$ 3.2$ comes for free when all the embedded predicate's individual arguments are saturated:

\footnotetext{
${ }^{29}$ Rev. Thomas Pruen. 1820. An illustration of the liturgy. London: W. Bulmer and W. Nicol, p. 146.

${ }^{30}$ Stephen Darwall. 2006. The second-person standpoint: Morality, respect, and accountability. Cambridge, MA: Harvard University Press, p. 67.
} 
(91)

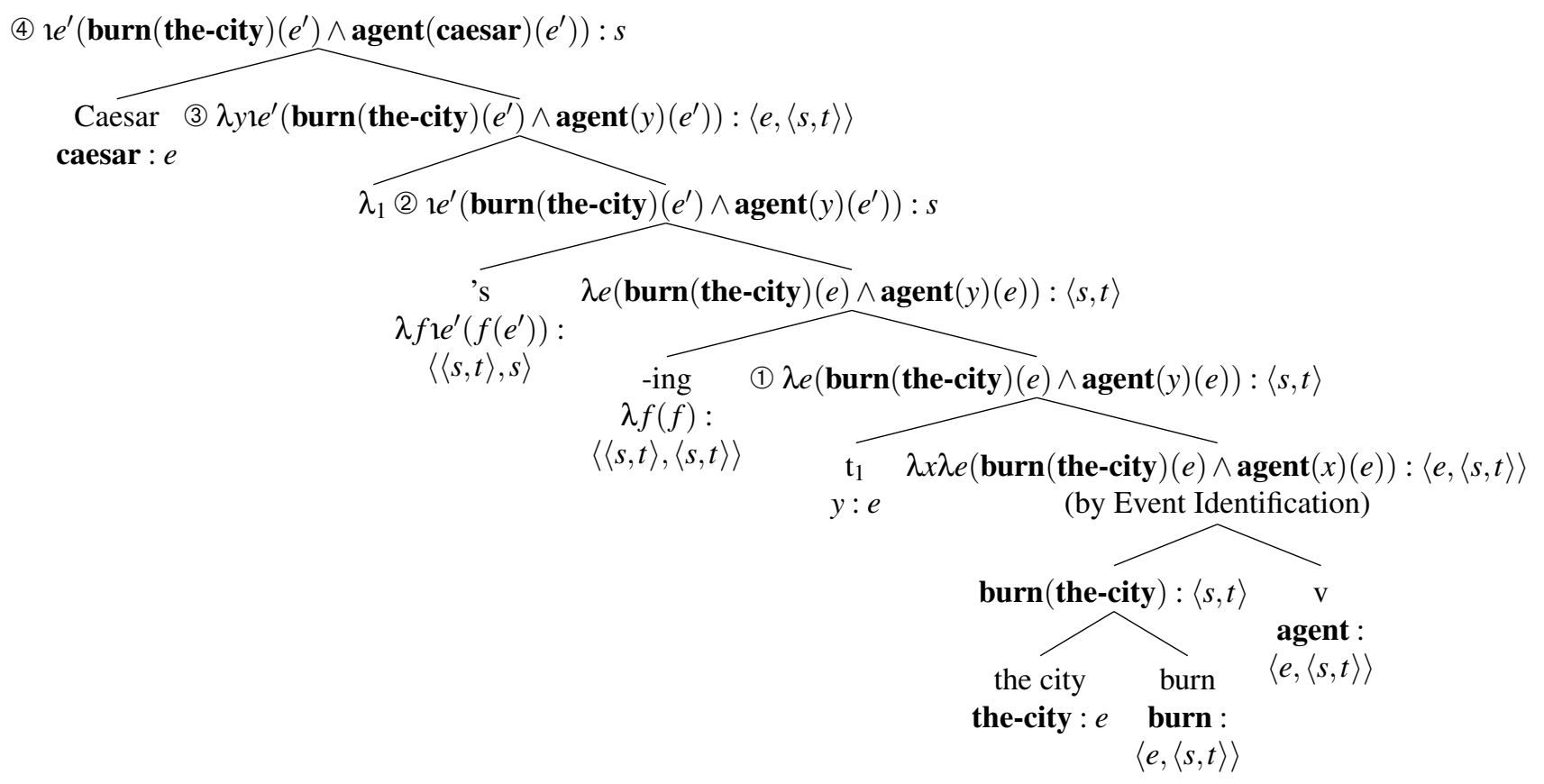

The embedded predicate of the POSs-ing gerund in (80a) only has its event argument left open (1). It would be existentially bound in a clause, but inside a nominalization the event argument is instead bound by the determiner (2). Abstraction over the trace of the external argument, which has raised to Spec-DP, creates a function from individuals to events (ignoring the intermediate trace in Spec-PossP) (3). This function applies to the external argument in Spec-DP, so that the gerund describes the event of Caesar burning the city (4)).

The POSS-ing gerund does not have an individual interpretation like nominalizations with -na in Northern Paiute because English has no way of constructing the relevant kind of dependency inside nominalizations. It lacks true resumptive pronouns, as resumption is only used as a rescue strategy when movement is not possible (Chao and Sells 1983, Sells 1984). Consequently, it is not possible for an internal argument of the verb in a POSS-ing gerund to be gapped, regardless of whether this gap is null or overt:

$$
\text { *I witnessed }\left\{\begin{array}{l}
\text { Caesar's burning } \\
\text { Caesar's burning it }
\end{array}\right\} \text {. }
$$

Intended: 'I witnessed what Caesar burnt.'

In addition, as a reviewer points out, English also lacks the operators that would abstract over a resumptive pronoun. After all, there are some variable-denoting expressions that can appear inside the POSS-ing gerund. The subject can be gapped, as shown in (93), yet no individual interpretation is possible.

$$
\text { Finding oneself is hard work. }
$$

Assuming that the external argument of the verb here is saturated by PRO (Abney 1987:168), the gerund would describe an individual if a $\lambda$-operator in English could bind it. But there must be no such operator in English because PRO receives an arbitrary interpretation and the gerund describes an event. 
In sum, the POSS-ing gerund has essentially the same structure as a nominalization with -na in Northern Paiute. It does not exhibit the same interpretive variability, though, because English does not have the system of resumptive pronouns and operators to bind them that would give rise to an individual interpretation. Consequently, the POSS-ing gerund only has an event interpretation.

\subsection{The agent nominalization in English}

At first glance, agent nominalizations with -er in English might look parallel to nominalizations with $-d \dot{i}$ in Northern Paiute. They actually diverge quite significantly in both their syntax and their semantics.

The agent nominalizations created by -er are significantly less verb-like than the POSS-ing gerund in English: i) they cannot assign accusative case to the direct object (*the seller the counterfeit stock); and, ii) they cannot be modified by adverbs (*the frequently seller of the counterfeit stock). In contrast, nominalizations with $-d \dot{t}$ pattern with the POSS-ing gerund in these respects see $\S 2$.

Moreover, nominalizations with -er describe individuals bearing a restricted set of theta roles. In (94), repeated from (80b) above, the nominalization describes the agent of the embedded verb.

The seller of counterfeit stock was jailed.

Rappaport Hovav and Levin (1992) show that -er creates nominalizations that describe any external argument theta role, as shown in $(95 \mathrm{a}-\mathrm{c})$. But they can NEVER describe an internal argument. The nominalizations of unaccusative verbs in (96) are all ungrammatical.

(95) a. The banya as an institution struck me as one of the few great levelers of Soviet society.

b. If you are the holder of a Visa or MasterCard charge card, you know they are accepted at hotels...

c. Jobs are the best indicator of a sound economy.

(Rappaport Hovav and Levin 1992:130f.)

*appearer, *collapser, *dier, *disappearer, *emanator, *ender, *exister, *happener, *laster, *occurrer, *transpirer, *waner, *wilter

(Rappaport Hovav and Levin 1992:148)

This contrasts strikingly with $-d \dot{t}$, which we saw in $\$ 4$ applies to both unaccusative and passive verbs to create nominalizations that describe an internal argument.

To account for its properties, Baker and Vinokurova (2009) propose that -er realizes a nominal functional head, which I will call $\mathrm{n}$, that introduces an external argument theta role (see also Bowers 2011:1200ff.): 
(97)

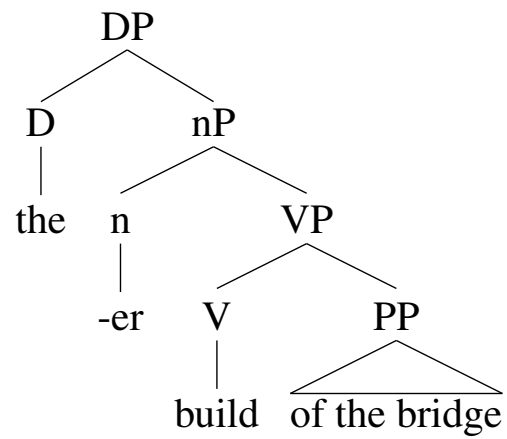

The -er nominalizer realizes this $\mathrm{n}$ head when it takes a VP complement. This derives the syntactic properties of agent nominalizations. Since $\mathrm{v}$ is not present inside this nominalization, the internal argument must be projected inside a PP and there can be no left-edge adverbs.

Baker and Vinokurova's proposal accounts for why agent nominalizations only have an individual interpretation. Unlike both the $-n a$ and $-d \dot{t}$ nominalizers in Northern Paiute and -ing in English, the -er suffix itself contributes the agent theta role in agent nominalizations ( $G$ is the generic operator):

$$
\llbracket \text {-er } \rrbracket=\lambda f \lambda x \mathrm{Ge}(f(e) \wedge \operatorname{agent}(x)(e)):\langle\langle s, t\rangle,\langle e, t\rangle\rangle
$$

Simplifying Baker and Vinokurova's lexical entry (p. 531) somewhat, the -er nominalizer takes a property of events and returns the set of individuals who are generic agents in those events. ${ }^{31}$ The nominalization in (97) consequently describes the individual who is the agent of an event of building the bridge. It can never have an event interpretation because the event argument of the verb is closed off through generic quantification by the -er suffix itself.

\section{Conclusion}

Northern Paiute has two types of deverbal nominalization that have the internal structure of a vP and the external distribution of a DP. Unlike similar patterns of nominalization in English, these can describe either an event or an individual. I have proposed that this range of interpretations arises through the interaction of the syntax of the nominalizers themselves, on the one hand, and the presence of operators that can abstract over a variable, on the other hand.

If the $-n a$ and $-d i$ nominalizers in Northern Paiute realize Poss, the nominal functional head that canonically assigns genitive case, the event interpretation comes for free in a certain sense. Under a Davidsonian event semantics, the verb takes an event argument that can remain unsaturated in

\footnotetext{
${ }^{31}$ Baker and Vinokurova actually give the lexical entry for $-e r$ in (i), where ${ }^{\cap}$ is Chierchia's nominalization operator. It is a function from properties of events to the individual correlate of the property of usually being the agent in such events:

$$
\llbracket \text {-er } \rrbracket=\lambda f^{\cap \lambda} \lambda x \mathrm{G} e(f(e) \wedge \operatorname{agent}(x)(e)):\langle\langle s, t\rangle, e\rangle
$$

It is not clear to me why the -er nominalizer needs to return an individual correlate as opposed to a predicate. By lowering the property of being an agent to its individual correlate with the $\cap$ operator, the determiner would have to encode the inverse $\cup$ operator to lift the individual correlate to a predicate again, in the way that Chierchia (1998) describes.
} 
these nominalizations. In contrast, in agent nominalizations in English, there is never an event interpretation because the -er nominalizer itself binds of the event variable of the verb.

The individual interpretations for deverbal nominalizations in Northern Paiute arise because the language has operators inside the DP that can abstract over a variable-contributing expression. For nominalizations with $-n a$, the variable is contributed by a resumptive pronoun, which can occur anywhere except as the highest argument of the verb. In POSS-ing gerunds, which otherwise have a nearly identical structure, only an event interpretation is possible because English lacks the operators and resumptive pronouns needed to construct an individual interpretation. For nominalizations with $-d \dot{t}$, the variable is contributed by a phonologically null element that does not need to be get case (PRO), which is projected as the highest argument of the verb.

Deverbal nominalizations comprise a diverse class across languages. As we have seen, however, despite variability in both their structure and interpretation, there are patterns and regularities, which I have sought to capture in the syntax of nominalizers themselves and the semantic resources available in a language.

\section{References}

Abney, Steven. 1986. Functional elements and licensing. Ms., Paper presented at Generative Linguistics in the Old World, Gerona, Spain., URL http://www.vinartus.net/spa/86b.pdf.

Abney, Steven. 1987. The English noun phrase in its sentential aspect. Ph.D. Dissertation, Massachusetts Institute of Technology.

Alexiadou, Artemis. 2001. Functional structure in nominals: Nominalization and ergativity. Amsterdam: John Benjamins.

Alexiadou, Artemis, Liliane Haegeman and Melita Stavrou. 2007. Noun phrase in the generative perspective. Berlin: Mouton de Gruyter.

Alexiadou, Artemis, Gianina Iordăchioaia and Elena Soare. 2010. Number/aspect interactions in the syntax of nominalizations: A Distributed Morphology approach. Journal of Linguistics 46:536-574.

Asher, Nicholas. 1993. Reference to abstract objects in discourse. Dordrecht: Kluwer.

Babel, Molly, Andrew Garrett, Michael J. Houser and Maziar Toosarvandani. To appear. Descent and diffusion in language diversification: A study of Western Numic dialectology. International Journal of American Linguistics .

Babel, Molly, Michael J. Houser and Maziar Toosarvandani. 2012. Mono Lake Northern Paiute. Journal of the International Phonetic Association 42:233-243.

Baker, Mark C. 1985. Syntactic affixation and English gerunds. West Coast Conference on Formal Linguistics (WCCFL) 4:1-11.

Baker, Mark C. 2005. On gerunds and the theory of categories. Ms., Rutgers University, URL http://www.rci.rutgers.edu/ mabaker/gerunds\&cattheory.pdf.

Baker, Mark C. and Nadya Vinokurova. 2009. On agent nominalizations and why they are not like event nominalizations. Language 85:517-556.

Barker, Chris. 1995. Possessive descriptions. Stanford, CA: CSLI.

Barker, Chris. 2011. Possessives and relational nouns. In Semantics: An international handbook of natural language meaning, eds. Claudia Maienborn, Klaus von Heusinger, and Paul Portner, volume 2, 1109-130. Berlin: Walter de Gruyter. 
Barwise, John and Robin Cooper. 1981. Generalized quantifiers and natural language. Linguistics and Philosophy 4:159-219.

Basilico, David. 1996. Head position and internally headed relative clauses. Language 72:498532.

Borer, Hagit. 1984. Restrictive relatives in Modern Hebrew. Natural Language and Linguistic Theory 2:219-260.

Borer, Hagit. 2003. Exo-skeletal vs. endo-skeletal explanations: Syntactic projections and the lexicon. In The nature of linguistic theory, eds. John Moore and Maria Polinsky, 31-67. Stanford, CA: CSLI Publications.

Borer, Hagit. 2005. In name only. Oxford: Oxford University Press.

Borsley, Robert and Jaklin Kornfilt. 2000. Mixed extended projections. In The nature and function of syntactic categories, ed. Robert Borsley, volume 32 of Syntax and Semantics, 101-131. New York: Academic Press.

Bowers, John. 2011. Non-event nominals and argument structure. Lingua 121:1194-1206.

Bresnan, Joan. 1997. Mixed categories as head sharing constructions. LFG Conference 2. URL http://csli-publications.stanford.edu/LFG/2/bresnan-lfg97.pdf.

Caponigro, Ivano. 2003. Free not to ask: On the semantics of free relatives and wh-words crosslinguistically. Ph.D. Dissertation, University of California, Los Angeles.

Cardinaletti, Anna. 1998. On the deficient/strong opposition in possessive systems. In Possessors, predicates, and movement in the determiner phrase, eds. Artemis Alexiadou and Chris Wilder, 17-54. Amsterdam: John Benjamins.

Carstens, Vicki. 2000. Concord in Minimalist theory. Linguistic Inquiry 31:319-355.

Chao, Wynn and Peter Sells. 1983. On the interpretation of resumptive pronouns. North East Linguistic Society (NELS) 13:47-61.

Chierchia, Gennaro. 1998. Reference to kinds across languages. Natural Language Semantics 6:339-405.

Chomsky, Noam. 1961. On the notion 'rule of grammar'. Proceedings of the Symposia in Applied Mathematics 12:6-24.

Chomsky, Noam. 1970. Remarks on nominalization. In Readings in English Transformational Grammar, eds. Roderick A. Jacobs and Peter S. Rosenbaum, 184-221. Waltham, MA: Ginn and Company.

Chomsky, Noam. 1977. On WH movement. In Formal syntax, eds. Peter W. Culicover, Thomas Wasow, and Adrian Akmajian, 71-132. New York: Academic Press.

Chomsky, Noam. 1981. Lectures on government and binding: The Pisa lectures. Amsterdam: Foris.

Chomsky, Noam. 2000. Minimalist inquiries: The framework. In Step by step: Essays on Minimalist syntax in honor of Howard Lasnik, eds. Roger Martin, David Michaels, and Juan Uriagereka, 89-156. Cambridge, MA: MIT Press.

Cinque, Guglielmo. 1999. Adverbs and functional heads: A crosslinguistic perspective. Oxford: Oxford University Press.

Comrie, Bernard. 1976. The syntax of action nominals: A cross-language study. Lingua 40:177201.

Comrie, Bernard and Sandra A. Thompson. 2007. Lexical nominalization. In Grammatical categories and the lexicon, ed. Timothy Shopen, volume 3 of Language Typology and Syntactic Description, 334-381. Cambridge: Cambridge University Press, 2nd edition. 
Davidson, Donald. 1967. The logical form of action sentences. In The logic of decision and action, ed. Nicholas Rescher, 81-95. Pittsburgh, PA: University of Pittsburgh Press.

Engdahl, Elisabet. 1985. Parasitic gaps, resumptive pronouns, and subject extractions. Linguistics 23:3-44.

Golla, Victor. 2011. California Indian languages. Berkeley: University of California Press.

Grimshaw, Jane. 1990. Argument structure. Cambridge, MA: MIT Press.

Hacquard, Valentine. 2010. On the event relativity of modal auxiliaries. Natural Language Semantics 18:79-114.

Heim, Irene. 1982. The semantics of definite and indefinite noun phrases. Ph.D. Dissertation, University of Massachusetts, Amherst.

Heim, Irene. 1998. Anaphora and semantic interpretation: A reinterpretation of Reinhart's approach. MIT Working Papers in Linguistics 25:205-246.

Heim, Irene and Angelika Kratzer. 1998. Semantics in Generative Grammar. Oxford: Blackwell.

Horn, G. M. 1975. On the nonsentential nature of the Poss-ing construction. Linguistic Analysis 1:333-387.

Horrocks, Geoffrey and Melita Stavrou. 1987. Bounding theory and Greek syntax: Evidence for wh-movement in NP. Journal of Linguistics 23:79-108.

Hudson, Richard. 2003. Gerunds without phrase structure. Natural Language and Linguistic Theory 21:579-615.

Jackendoff, Ray. 1977. X-bar syntax: A study of phrase structure. Cambridge, MA: MIT Press.

Jacobson, Pauline. 1995. On the quantificational force of English free relatives. In Quantification in natural languages, eds. Emmon Bach, Eloise Jelinek, Angelika Kratzer, and Barbara H. Partee. Dordrecht: Kluwer.

Jensen, Per Anker and Carl Vikner. 1994. Lexical knowledge and the semantic analysis of Danish genitive constructions. In Topics in knowledge-based NLP systems, eds. Steffen Leo Hansen and Helle Wegener, 37-55. Copenhagen: Samfundslitteratur.

Koopman, Hilda. 1992. Control from COMP and comparative syntax. The Linguistic Review 2:365-391.

Koptjevskaja-Tamm, Maria. 1993. Nominalizations. London: Routledge.

Kornfilt, Jaklin. 1984. Case marking, agreement, and empty categories in Turkish. Ph.D. Dissertation, Harvard University.

Kornfilt, Jalkin and John Whitman. 2011. Afterword: Nominalizations in syntactic theory. Lingua 121:1297-1313.

Koster, Jan. 1975. Dutch as an SOV language. Linguistic Analysis 1:111-136.

Kratzer, Angelika. 1996. Severing the external argument from its verb. In Phrase structure and the lexicon, eds. J. Rooryck and L. Zaring, 109-137. Dordrecht: Kluwer.

Krause, Cornelia. 2001. On reduced relatives with genitive subjects. Ph.D. Dissertation, Massachusetts Institute of Technology.

Laka, Itziar. 1990. Negation in syntax: On the nature of functional categories and projections. Ph.D. Dissertation, Massachusetts Institute of Technology.

Liljeblad, Sven. 1966. Northern Paiute manual I: Grammatical sketch of the northern dialects. Boise, ID: Department of Anthropology, Idaho State University.

Mailing, Joan and Soowon Kim. 1992. Case assignment in the inalienable possession construction in Korean. Journal of East Asian Linguistics 1:37-68.

Malouf, Robert. 2000a. Mixed categories in the hierarchical lexicon. Stanford, CA: CSLI Publi- 
cations.

Malouf, Robert. 2000b. Verbal gerunds as mixed categories in HPSG. In The nature and function of syntactic categories, ed. Robert D. Borsley, number 32 in Syntax and Semantics, 133-166. New York: Academic Press.

McCloskey, James. 1990. Resumptive pronouns, Ā-binding and levels of representation in Irish. In Syntax of the modern Celtic languages, ed. Randall Hendrick, volume 23 of Syntax and Semantics, 199-248. San Diego: Academic Press.

McCloskey, James. 2006. Resumption. In The Blackwell companion to syntax, eds. Martin Everaert and Henk van Riemsdijk, volume 4, 94-117. Oxford: Blackwell.

Milsark, G. L. 1988. Singl-ing. Linguistic Inquiry 19:611-634.

Mugane, John M. 2003. Hybrid constructions in Gĩkũyũ: Agentive nominalization and infinitivegerund constructions. In Nominals: Inside and out, eds. Miriam Butt and Tracy Holloway King, 235-265. Stanford, CA: CSLI Publications.

Panagiotidis, E. Phoevos and Kleanthes K. Grohmann. 2009. Mixed projections: Categorial switches and prolific domains. Linguistic Analysis 36:141-161.

Partee, Barbara H. 1997. Uniformity vs. versatility: The genitive, a case study. In The handbook of logic and language, eds. Johan van Benthem and Alice ter Meulen, 464-470. New York: Elsevier.

Partee, Barbara H. and Vladimir Borschev. 1998. Integrating lexical and formal semantics: Genitives, relational nouns, and type-shifting. In Proeedings of the second Tblisi symposium on language, logic, and computation, eds. R. Cooper and Th. Gamkrelidze, 229-241. Tblisi: Center on Language, Logic, and Speech, Tblisi State University.

Partee, Barbara H. and Vladimir Borschev. 2002. Genitives, relational nouns, and argumentmodifier ambiguity. In Modifying adjuncts, eds. Ewald Lang, Claudia Maienborn, and Cathrine Fabricius-Hansen, 67-112. Berlin: Mouton de Gruyter.

Pollock, Jean-Yves. 1989. Verb movement, Universal Grammar, and the structure of the IP. Linguistic Inquiry 20:365-424.

Portner, Paul. 1992. Situation theory and the semantics of propositional expressions. Ph.D. Dissertation, University of Massachusetts, Amherst.

Pullum, Geoffrey. 1991. English nominal gerund phrases as noun phrases with verb-phrase heads. Linguistics 29:763-799.

Pustejovsky, James. 1993. Type coercion and lexical selection. In Semantics and the lexicon, ed. James Pustejovsky, 73-94. Dordrecht: Kluwer.

Pustejovsky, James. 1995. The generative lexicon. Cambridge, MA: MIT Press.

Radford, Andrew. 2000. NP shells. Ms., University of Essex, URL http://privatewww.essex.ac.uk/ $\sim$ radford/PapersPublications/npshells.htm.

Rappaport Hovav, Malka and Beth Levin. 1992. - er nominals: Implications for the theory of argument structure. In Syntax and the lexicon, eds. Timothy Stowell and Eric Wehrli, volume 26 of Syntax and Semantics, 127-153. San Diego, CA: Academic Press.

Reinhart, Tanya. 1983a. Anaphora and semantic interpretation. Chicago: University of Chicago Press.

Reinhart, Tanya. 1983b. Coreference and anaphora: A restatement of the anaphora question. Linguistics and Philosophy 6:47-88.

van Riemsdijk, Henk. 1998. Head movement and adjacency. Natural Language and Linguistic Theory 16:633-678. 
Schachter, Paula. 1976. A nontransformational accout of gerundive nominals in English. Linguistic Inquiry 7:205-241.

Sells, Peter. 1984. Syntax and semantics of resumptive pronouns. Ph.D. Dissertation, University of Massachusetts, Amherst.

Snapp, Allen, John Anderson and Joyce Anderson. 1982. Northern Paiute. In Studies in UtoAztecan grammar, ed. Ronald W. Langacker, volume 3, 1-92. Dallas: Summer Institute of Linguistics and the University of Texas.

Sportiche, Dominique. 1998. Movement, agreement, and case. In Partitions and atoms of clause structure: Subjects, agreement, case, and clitics, 88-243. New York: Routledge.

Szabolcsi, Anna. 1983. The possessor that ran away from home. Linguistic Review 3:89-102.

Szabolcsi, Anna. 1987. Functional categories in the noun phrase. In Approaches to Hungarian, ed. István Kenesei, volume 2, 167-189. Jate Szeged.

Szabolcsi, Anna. 1989. Noun phrases and clauses: Is DP analogous to IP or CP? Ms., New York University, URL http://files.nyu.edu/as109/public/szabolcsi\%20DP\%20IP\%20CP.pdf.

Szabolcsi, Anna. 1994. The noun phrase. In The syntactic structure of Hungarian, ed. Ferenc Kiefer, volume 27 of Syntax and Semantics. New York: Academic Press.

Thornes, Tim. 2003. A Northern Paiute grammar with texts. Ph.D. Dissertation, University of Oregon.

Toosarvandani, Maziar. 2011. The role of nominalization in Northern Paiute relative clause formation. Workshop on Structure and Constituency of Languages of the Americas (WSCLA) 16:151165.

Valois, Daniel. 1991. The internal syntax of DP. Ph.D. Dissertation, University of California, Los Angeles.

Yoon, James Hye Suk. 1996. Nominal gerund phrases in English as phrasal zero derivations. Linguistics 34:329-356.

Zucchi, Alessandro. 1993. The language of propositions and events. Dordrecht: Kluwer Academic Publishers.

Department of Linguistics and Philosophy

Massachusetts Institute of Technology

32-D808

Cambridge, MA 02139

toosarva@mit.edu

http://toosarva.scripts.mit.edu/ 